\title{
An Investigation on Abrasive Wear Characteristics of Thermoplastic Composites Under Conditions of Different Loads and Sliding Speeds
}

Ashish Soni ( $\square$ ashishsoni1209@gmail.com )

National Institute of Technology Agartala https://orcid.org/0000-0003-0807-412X

Pankaj Kumar Das

National Institute of Technology Agartala

\section{Research Article}

Keywords: Three-body abrasion, Wear, Polymeric composites, Tribology, Load and sliding speed, ASTM G65, Wear morphology

Posted Date: November 12th, 2021

DOI: https://doi.org/10.21203/rs.3.rs-1053013/v1

License: (a) (i) This work is licensed under a Creative Commons Attribution 4.0 International License. Read Full License 


\section{Abstract}

The diverse nature of polymer with attractive properties is replacing the conventional materials with polymeric composites. The present study is sought to evaluate the wear performance of thermoplastic based composites under the conditions of different loads and sliding speeds. A series of nine different composite materials was developed by using low-density polyethylene (LDPE), high-density polyethylene (HDPE), and polyethylene terephthalate (PET) with replacements of sand i.e. 0, 30, 40, and $50 \mathrm{wt}$.\%. The abrasive wear was evaluated by following the ASTM G65 standard test for abrasive wear through dry-sand rubber wheel apparatus under the applied loads of $34.335,56.898,68.719,79.461$ and $90.742(\mathrm{~N})$, and sliding speeds of $0.05388,0.7184,0.8980,1.0776$ and $1.4369(\mathrm{~m} / \mathrm{s})$. The results showed the wear response varies non-linearly with load and sliding speed. The possible correlations between wear and mechanical properties, and throughout discussions for wear behaviors with morphological study of the worn surfaces were provided.

\section{Introduction}

Friction and wear (tribology) are the two generally used terms in our day-to-day lives. The friction is advantageous for performing our activities. Despite the several advantages offered by friction there remains no doubt that all the moving parts from big to small machinery and equipment are succumbing to the problem of friction and wear out. It is estimated that approximately $23 \%$ of the global energy consumption is lost due to friction and wear i.e. tribological contact, out of which $20 \%$ is accounted for overcoming the friction and the rest $3 \%$ is consumed to replace and remanufacture the worn-out parts [1,2]. Moreover, friction and wear remains the cause of concern for the environment due to association of harmful effects of lubrication that are widely usages to reduce friction [3] hence gains the importance of the study of friction and wear in different sectors of the globe. Depending on the types of loading and materials wear is mainly classified as sliding wear, fretting wear, abrasive wear, and cavitation. Among the mentioned types of wear, abrasive wear is considered as the costliest form of wear [4] making the study of abrasion an important since the industrial revolution thereafter many experiments had been conducted for studying abrasive wear with the application of various test methods. The abrasion wear test is widely used for the evaluation of abrasion wear of mechanical components, construction component and protective coating [5-6] and a good correlation was established between the experimental results with field tests [7-8]. The studies had revealed the abrasive wear in two different modes as two- and three-body abrasive wear with some significant differences [9]. In two-body abrasive wear the material is removed by passing of the hard asperities or rigidly held grits over the surface like a cutting tool which can be exemplified as the action of sandpaper on a surface whereas in three-body abrasive wear the grits are not held rigidly and are free to slide as well as rollover the surface $[10,11]$. Two-body wear is more often a subject of scientific research whereas three-body wear is arguably more important industrially [12-14]. The dry sand- rubber wheel (DSRW) test is a commonly employed test for the three-body abrasion and is widely used to evaluate low-stress abrasive wear of the material [15]. The employed setup and principle of the tests are held within G65 ASTM standard [16] the test types are predated by the Brinell abrasion testing machine [17]. The contact is maintained between the rotating rubber wheel and target specimen through the dead weights provided for loading under a certain constant speed and a stream of sand particles is continuously fed that transverses through contact either by embedding into the rubber wheel or by rolling which produces a groove in the test specimen. The evaluation 
for the volume loss indicates abrasive resistance as a lower value of volume loss indicates a higher wear resistance and vice-versa also it establishes a good agreement with the laboratory test and practices $[18,19]$. In a dry sand-rubber wheel (DSRW) abrasion wear test the volume loss of the test specimen during test is proportional to the load applied hence the test is performed at constant sliding speed similarly the load is kept constant while test is performed under different speeds. Howorth [20] had noticed that on application of high load the wear rate is greater than expected with a non-linear behavior for load and wear rate. The load relation was found to influence by the hardness of the rubber on the wheel [21]. Moreover, the abrasive wear response depends on the material properties of the test piece, testing conditions includes particle type, shape, size, frangibility, etc. properties of the wheel like hardness, stiffness, etc. and the ambient conditions [22]. ASTM has specified wear test with fixed load and speed for ranking of engineering materials into different classes [23]. However, such ranking is inaccurate and generates misleading information which could happen due to the interdependency of abrasive wear on several factors like encountering forces, surface properties, material properties, testing conditions such as load applied and sliding speed and abrasive packing fraction making it a complex process [24]. The study had showed that under the condition of dry sand-rubber wheel abrasion the wear loss is directly proportional to the applied load only at the condition of lower loadings however the wear behavior becomes irregular at higher loading conditions [25]. Moreover, the wear was observed to depend upon the hardness of the rubber wheel due to the effect of the contact area between the wheel and specimen [26]. The different properties of the reinforcement and fillers can significantly influence the tribological performance of the composites.

Plastics available in various forms are known to possess several remarkable properties. The typical characteristics of plastics like high stiffness, quite strength to weight ratio, lightweight, chemically inert, low friction coefficient, wear resistance, biocompatibility, high-temperature stability $[27,28]$ makes it a suitable material for applications in various fields includes aerospace, automotive, food processing, electrical and biomedical [29-31]. In the past few decades, the application of polymeric compounds is increasing rapidly due to low cost with efficient mechanical and tribological properties. The global market for engineering plastics is projected to Compound an Annual Growth Rate (CAGR) of $7 \%$ by the year 2023. The increase of plastic in the technologically driven world is a need for polymeric composites with effective tribological properties. The low density of plastics, lubricity, and high load-carrying capacity make it suitable for tribological application [32-34]. However, plastics suffer due to their poor abrasive resistance leading to a high wear rate $[35,36]$. The abrasive wear resistance of the plastics can be improved by reinforcement with sand particle which has shown feasibility to develop plastic-based composites to improve the tribological performance significantly [37-39]. The studies had noticed a significant improvement in tribological characteristics of a polymeric compound due to the branchy structure provided by fumed silica particles [4042]. The additives like fibers, whiskers, particles, $\mathrm{MoS}_{2}$ (solid lubricant) improves the tribological properties with reduced cost of the polymeric composites [43-45] making the development of fibers reinforced polymeric composites an important $[46,47]$. The various modification has been implemented for improving the wear resistance of plastics composites such as surface modification [48], micro-sized particles (bronze, $\mathrm{TiO}_{2}, \mathrm{MoS}_{2}$ ) [49], nano-and micro-sized particles, [49,50] carbon, graphite, glass fibers, graphite filled polyamide [51, 52]. It is also known that abrasive wear resistance for plastics is good under static load while for impact loads it was very high [53]. Moreover, wear of glass fabric composites with epoxy, polyether ketone, poly-phenylene sulfide and polyester had been carried out [54-60]. Earlier studies had reported that 
during application the materials are subjected to the conditions of variable speeds and forces that differ in magnitude. However, there is an absolute dearth of research for investigating the abrasive wear behavior under conditions of varying loading and sliding speed for a sustainable composite material developed by utilizing different waste plastics as reinforcement with full and partial sand replacement. To this end, the composites were prepared by using waste plastics of different types with the incorporation of sand by following the compositions as mentioned in Table 1. However, the objective of the work is to study the wear behavior of the developed sand-plastic based composite materials under the dry sand-rubber wheel abrasion condition with special emphasis to investigate their behavior under condition of different loading and sliding speeds and identify the important factors which could be controlled to increase the wear resistance of the composites. In present a total of nine different sand-plastic based composite samples were prepared with different compositions and evaluations were carried for volume loss as abrasion wear under the condition of five different loads and sliding speeds. The study comparatively investigates the abrasive wear behavior of sand-plastic based composites developed by using different types of plastics includes low-, high density polyethylene, and polyethylene terephthalate as reinforcement and sand as filler under conditions of different loads and speeds using dry sand - rubber wheel apparatus. It was observed that the wear response of each sample behaves differently with loads and sliding speeds. Examination for the wear surfaces was conducted with a complete morphological characterization of the wear-out surfaces was conducted by using an optical microscope of a Leica DMI $3000 \mathrm{M}$. The correlation between the wear mechanism and mechanical properties has been established.

Table 1

Table of composition for the prepared samples

\begin{tabular}{|llllll|}
\hline S. No & Sample designation & $\begin{array}{l}\text { LDPE } \\
\text { (Wt. \%) }\end{array}$ & $\begin{array}{l}\text { HDPE } \\
\text { (Wt. \%) }\end{array}$ & $\begin{array}{l}\text { PET } \\
\text { (Wt. \%) }\end{array}$ & $\begin{array}{l}\text { Sand } \\
\text { (Wt. \%) }\end{array}$ \\
\hline 1 & LDPE50 & 50 & - & - & 50 \\
\hline 2 & LDPE60 & 60 & - & - & 40 \\
\hline 3 & LDPE70 & 70 & - & - & 30 \\
\hline 4 & LDPE100 & 100 & - & - & - \\
\hline 5 & HDPE50 & - & 50 & - & 50 \\
\hline 6 & HDPE60 & - & 60 & - & 40 \\
\hline 7 & HDPE70 & - & 70 & - & 30 \\
\hline 8 & HDPE100 & - & 100 & - & - \\
\hline 9 & LDPE50 PET20 & 50 & - & 20 & 30 \\
\hline
\end{tabular}

\section{Experimental Details}


The composites were prepared by using natural silica sand with reinforcement of three types of waste plastics includes low-density polyethylene, high-density polyethylene, and polyethylene terephthalate. The properties of the waste plastics used are listed in Table 2. The silica sand is having a grain size of $600 \mu \mathrm{m}$ is used as filler material. The values for bulk density and specific gravity of the sand were found to be 1730 $\mathrm{kg} / \mathrm{m}^{3}$ and 2.65 respectively at ambient conditions. Fig. 1 gives the Process flow chart for the procedure followed for preparation of the composite samples. Initially, waste plastic bags were collected from different waste collecting points in the municipality. The collected waste plastics were cut to open and washed thoroughly to remove any impurities then dried completely. The processed plastics waste material (polythene bags, sachet water bags, wrappers, bottles, etc.) are sorted and shredded into small pieces. The different plastics waste were mixed with sand as per the proportion listed in Table 1. The raw materials as the composition was melted up to its semi-solid condition. The mixture is mixed continuously until a homogenous blend of sand and plastic mixture are formed. The composites were casted through the static compaction method. The pressure was applied through a manually driven reaction frame system with a vertical guiding rod which can be moved up and down by rotating. The semi-solid mixture is placed into the open compression mould and was forced to conform to the shape of the mould. Once moldings are finished excess flash is removed and prepared to obtain the required dimension for testing. Fig. 2 (a-i) gives the images of the specimens prepared by following the composition as proposed. Further to identify the surfaces of the prepared samples microstructural examination was conducted using an optical microscope of Leica DMI 3000M and is shown in Figure $3(\mathrm{a}-\mathrm{i})$. The sand particles were observed to uniformly distribute with the reinforcement. However, porosity is observed mainly around the tip of the particle and reduces with the decrease of sand particle. The decrease in porosity can be attributed to the improvement in the fluidity of the melt due to reduced melting temperature [62]. The prepared composite specimens were used to investigate the effect on abrasive wear under the given different conditions of loadings and sliding speeds.

Table 2

Properties of waste plastics

\begin{tabular}{|c|c|c|c|c|c|c|c|c|}
\hline \multirow{2}{*}{$\begin{array}{l}\text { S. } \\
\text { No }\end{array}$} & \multirow{2}{*}{$\begin{array}{l}\text { Type } \\
\text { of } \\
\text { plastic }\end{array}$} & \multicolumn{7}{|l|}{ Property } \\
\hline & & $\begin{array}{l}\text { Coefficient } \\
\text { of linear } \\
\text { thermal } \\
\text { expansion } \\
\text { (in/ } \\
{ }^{\circ} \mathrm{F} \times 10^{-5} \text { ) }\end{array}$ & $\begin{array}{l}\text { Tensile } \\
\text { strength } \\
\text { (Psi) }\end{array}$ & $\begin{array}{l}\text { Tensile } \\
\text { Modulus } \\
\text { of } \\
\text { elasticity } \\
\text { (Psi) }\end{array}$ & $\begin{array}{l}\text { Tensile } \\
\text { Elongation } \\
(\%)\end{array}$ & $\begin{array}{l}\text { Flexural } \\
\text { Strength } \\
\text { (Psi) }\end{array}$ & $\begin{array}{l}\text { Flexural } \\
\text { Modulus } \\
\text { of } \\
\text { Elasticity } \\
\text { (Psi) }\end{array}$ & $\begin{array}{l}\text { Heat } \\
\text { Deflection } \\
\text { Temperature } \\
\left({ }^{\circ} \mathrm{F}\right)\end{array}$ \\
\hline 1 & LDPE & - & 1400 & - & 500 & - & 30,000 & $122-$ \\
\hline 2 & HDPE & 9.0 & 4000 & - & 600 & - & 200,000 & $172-$ \\
\hline 3 & PET & 5.0 & 11500 & 400,000 & 70 & 15000 & 400000 & $240-175$ \\
\hline
\end{tabular}

\subsection{Abrasion Tester}

The dry sand-rubber wheel apparatus based on ASTM G65 standard [61] is schematically illustrated in Fig. 4. Dry Abrasion Tester TR- 50 build by ducom Instruments Pvt. Ltd. an ISO: 9001:2008 certified company as shown in Fig. 5 is employed for abrasive wear test. The design of the dry abrasion wear tester is based on the report by Stevenson and Hutchings 1996 [63].The rubber wheel is mounted over the spindle made of a steel 
disc with an outer layer of chlorobutyl rubber molded to its periphery. The wheel is having a diameter of 228.6 $\mathrm{mm}$ with hardness of Durometer A-60. The specimen is pressed against the rubber wheel by an L-shaped loading lever having a loading ratio of $1: 2.32$ having an initial load of $3.5 \mathrm{~kg}$. The rubber wheel is driven by a $2 \mathrm{HP}$ motor coupled with a reduction gearbox of gear ratio 7:1. The gear ratio is designed to ensure full torque is delivered from low speed up to the maximum speed of $200 \mathrm{rpm}$. The rotation of the wheel is such that the contact surface moves in the direction of sand flow. The pivot axis of the lever arm lies in a plane that is approximately tangent to the surface of the rubber wheel and normal to the horizontal diameter along which the load is applied. The test duration and force applied by the lever arm can be varied. The specimen holder is a part of the lever arm and maintains contact with the rubber wheel at the center to transfer the force along its horizontal diametrical line. The specimen is pressed against the rubber wheel by the initial weight of the loading lever of $3.5 \mathrm{Kg}$ and to further increase the force on the specimen dead weights are placed on the loading pan hung from the lever end, an appropriate number of dead weights are provided for this purpose. The specimen holder is an integral part of the lever arm having an on the lever end to place and clamp specimen as shown in Fig. 6 . Usually the specimen-clamping size is $76 \times 25.4 \times 12.7(\mathrm{~mm})$ but with additional packing pieces of thickness 1,2 , and $4 \mathrm{~mm}$ it is possible to clamp in the holder by a side plate with screws.

The surface of the specimen used for the test is made smooth, flat and free from scale as surface defects like porosity and roughness will affect the test results. The abrasion wear occurs when abrasive passes between the rotating rubber wheel and specimen. The abrasive used is round quartz grain sand as specified by AFS $50 / 70$ test sand. Dried sand is filled inside the hopper having $15 \mathrm{~kg}$ capacity and flow of sand is regulated by operating the sand tap tab fitted below the hopper. The sand tap is made of a round shaft enclosed inside a rectangular piece having a corresponding hole. The sand is fed into the nozzle by gravity that flows through a seamless stainless steel nozzle. The nozzle end is shaped to produce an accurate sand flow of $354 \mathrm{gm}$. / min and passes between the specimen and rubber wheel.

\subsection{Three -body abrasion wear test}

Experimental tests were conducted by following the ASTM G65 standard for abrasive tests. Abrasion is calculated in terms of volume loss $\left(\mathrm{cm}^{3}\right)$ for the prepared specimens under the specified test conditions by following the compositions as shown in Table1. The bulk density of the composites was measured by using Archimedes principle with water as the immersing medium using Mettler Toledo ME204 balance with $0.1 \mathrm{mg}$ accuracy. The values of density of the prepared specimens are given in Table 3 and is plotted as Fig. 7. To determine the response of the prepared specimen under the experience of an external load the compressive strength of the specimens is evaluated by using a hydraulic universal testing machine (Model HL 59020) having the capacity of $600 \mathrm{KN}$. The test specimen was loaded gradually employing hydraulic pressure and the stress-strain data is recorded as the fracture point is reached the maximum load is recorded. Table 3 gives the resulted values for the compressive strength and plotted as Fig. 8. The AFS 60 grade silica sand (density $2.6 \mathrm{~g} / \mathrm{cm}^{3}$ and knop hardness 875 ) having an angular shape with sharp edges is used as the abrasive. The specimens were cleaned with acetone and dried completely before the test. The specimen was weighted with a high precision digital balance (Mettler, Toledo) having an accuracy of $0.1 \mathrm{mg}$. The dimensioned specimens $(76 \times 25.4 \times 12.7 \mathrm{~mm})$ was mounted in the sample holder and abrasive was introduced the rotating wheel (dia. $228.6 \mathrm{~mm} \times$ width $12.7 \mathrm{~mm}$ ) composed of chlorobutyl rubber (hardness: Durometer A 70-72). Fig. 9 shows the image specimen during abrasion test. The specimen holder is designed to ensure easy removal and 
replacement of samples. The values for the applied load on the wheel are calculated by the equation (i) given below.

Table 3

Density and compressive strength

\begin{tabular}{|llll|}
\hline S. N0 & Sample designation & Density $\left(\mathrm{g} / \mathrm{cm}^{3}\right)$ & $\begin{array}{l}\text { Compressive strength } \\
\left(\mathrm{N} / \mathrm{mm}^{2}\right)\end{array}$ \\
\hline 1 & LDPE50 & 1.5304 & 32.34 \\
\hline 2 & LDPE60 & 1.4574 & 29.35 \\
\hline 3 & LDPE70 & 1.1085 & 31.15 \\
\hline 4 & LDPE100 & 0.8404 & 26.07 \\
\hline 5 & HDPE50 & 2.0011 & 46.20 \\
\hline 6 & HDPE60 & 2.0555 & 44.50 \\
\hline 7 & HDPE70 & 1.7737 & 41.85 \\
\hline 8 & HDPE100 & 2.0361 & 37.66 \\
\hline 9 & LDPE50 PET20 & 1.6151 & 20.81 \\
\hline
\end{tabular}

Load on wheel $=($ dead weight $\times$ loading lever ratio + initial load $) \ldots . . .$. eq. (i)

The abrasive wheel rotates in the direction of sand flow while the plane of the pivot axis of the lever arm is tangent to the rubber wheel surface and normal to the horizontal diameter with the applied load. The difference in the weight of the specimen before and after abrasion is determined. The volume loss $\left(\mathrm{cm}^{3}\right)$ due to abrasion is calculated individually by equation (ii) under the applied loads of $34.335,56.898,68.719$, 79.461 , and $90.742(\mathrm{~N})$ keeping the rotation of the wheel fixed at $30 \mathrm{rpm}$. A similar procedure is followed under sliding speeds $\vee R(\mathrm{v}$ is angular speed and $R$ is the radius of the wheel) of $0.5388,0.7184,0.8980$, 1.0776 , and $1.4369(\mathrm{~m} / \mathrm{s})$ at a loading of $5.8 \mathrm{kgf}$.

Loss in volume $\left(\mathrm{mm}^{3}\right)=[$ Weight before test - Weight after test $(\mathrm{gm})] \times$. eq. (ii)

\section{Density $\left(\mathrm{gm} . / \mathrm{cm}^{3}\right)$}

\section{Results And Discussions}

Sliding, extruding and rolling are included as the relative motion between the abrasive particle and contacting surfaces. For the prepared samples it is observed that the abrasion takes due to the combination of the processes includes plastic deformation, micro- plowing, -cutting, interfacial debonding, and peeling of fibers which can be considered as the wear mechanism for the materials. A complex interaction between the abrasive sand particles and target specimens under dry sand-rubber wheel abrasion was observed. The sharp edges, tips and asperities of some abrasive particles would intent the abrading surface layer under compressive stress and plastic deformation. The contact area between the abrasive wheel and specimens as 
well as force on the abrasive particle changes with the applied loads and sliding speeds and influences the volume loss as abrasion of the specimens. The aim of incorporating sand into the polymer is to enhance the mechanical properties of specimens as compressive strength. The wear resistance improve significantly with compressive strength of the specimens but invariability is exist for wear behavior. To correlate the wear data several mechanisms has been proposed that explains the removal of material during abrasion but due to the complexity of abrasion no particular mechanism could completely contribute to all the wear mechanisms. The resulted values for the volume loss showed that the specimens with incorporation of sand are having better wear performance compared to specimens without sand due to the improved interaction between the filler and binder. The images of the typical wear scar showing damage morphologies for the specimens are shown in Fig. 10 (a-i). The examinations for the worn scars showed a similarity for the damage morphologies having three different zones includes a short entrance zone, the main central wear zone and the exit area. Moreover, at the entrance and exit zone the damage morphologies were consistent with rolling of abrasive particles due to less pressure whereas at the central wear zone high pressure causes sliding motion of abrasive particles and parallel grooves were formed. The shallow ridges similar to plowing were formed within the grooves and displaces the material. Additionally, long micro-cracks predominantly in the transverse direction and grooves formed by the micro-cutting were present in the wear direction.

\subsection{Wear loss with respect to the applied load}

Table 4 gives the resulted values for the volume loss as abrasion wear under the tested loads and plots for the volume loss against applied loads for the prepared samples is given as Fig. 11. The overall results for the abrasion wear under the different loads shows the minimum values of wear as $0.02498 \mathrm{~cm}^{3}$ for the specimen as HDPE50 at $34.335 \mathrm{~N}$ whereas, the maximum values of wear were found as $0.32671 \mathrm{~cm}^{3}$ for LDPE50 at the loading of $34.335 \mathrm{~N}$. Similarly, the observations for the wear at different sliding speeds observed the minimum values of wear as $0.03095 \mathrm{~cm}^{3}$ for the specimen as LDPE5OPET20 at sliding speed of $1.0776 \mathrm{~m} / \mathrm{s}$ and the maximum value of wear as $0.29983 \mathrm{~cm}^{3}$ for the specimen as HDPE50 at sliding speed of 1.4369 $\mathrm{m} / \mathrm{s}$. Hence, the wear has shown its dependency on applied load and compositions of the composite. At the condition of low applied loads the energy generated by abrasive particles is not sufficient to break the surface energy barrier created at the junction of the abrasive particle and the test specimen as a result the penetration of the abrasive particles into the matrix is restricted whereas at the conditions of high load the particles gain energy while rolling with the rubber wheel results in high wear. The energy barrier is more with the incorporation of sand into the plastics as matrices. The energy gained from the high-speed rubber wheel is sufficient for micro-cutting of the plastic-based composite [64-67]. The wear rate for LDPE composites at low value of initial loading i.e. $34.335 \mathrm{~N}$ is comparatively higher due to the increase instability of the abrasive grains. The comparative study of wear for the developed specimens at conditions of different applied loads i.e. $34.335,56.898,68.179,79.461$, and $90.742(\mathrm{~N})$ shows a comparatively superior wear resistance by the specimens as HDPE50, LDPE60, LDPE50PET20, LDPE70 and LDPE50 with volume loss of $0.02498,0.03430$, $0.03095,0.09020$ and $0.03267\left(\mathrm{~cm}^{3}\right)$ respectively. The wear decreases at higher applied load and the effect of the load becomes significant at low sliding speed and is quite similar to those reported in the earlier studies [68]. Also, an increase in contact area allows a large number of sand particles to encounter at the interface and share the stress leading towards the condition of steady-state or reduction in wear rate. At 
higher load i.e. $90.7425 \mathrm{~N}$ the volume loss increases for the HDPE and PET samples due to the deboning of sand whereas the LDPE samples showed better wear resistance at the higher load. It confirms that the combined effect of the fillers and matrix results to considerable improvement in abrasion wear resistance for the sand-plastic based composites at different loading due to the wear resistance provided by the filler during abrasion under a compressive load [69].

Table 4

Abrasive wear at different load

\begin{tabular}{|lllllll|}
\hline S. No & Sample designation & \multicolumn{4}{l}{ Wear rate $\left(\mathbf{c m}^{\mathbf{3}}\right)$ at loadings } \\
\cline { 3 - 7 } & & $\mathbf{3 4 . 3 3 5} \mathbf{~ N}$ & $\mathbf{5 6 . 8 9 8} \mathbf{N}$ & $\mathbf{6 8 . 1 7 9} \mathbf{~ N}$ & $\mathbf{7 9 . 4 6 1} \mathbf{~ N}$ & $\mathbf{9 0 . 7 4 2} \mathbf{~ N}$ \\
\hline 1 & LDPE50 & 0.32671 & 0.06534 & 0.06534 & 0.19602 & 0.03267 \\
\hline 2 & LDPE60 & 0.30876 & 0.03430 & 0.03430 & 0.10292 & 0.06861 \\
\hline 3 & LDPE70 & 0.27061 & 0.04510 & 0.04510 & 0.09020 & 0.09021 \\
\hline 4 & LDPE100 & 0.23796 & 0.05949 & 0.05949 & 0.11898 & 0.05949 \\
\hline 5 & HDPE50 & 0.02498 & 0.07495 & 0.12493 & 0.14991 & 0.14991 \\
\hline 6 & HDPE60 & 0.12162 & 0.09729 & 0.07297 & 0.09729 & 0.14594 \\
\hline 7 & HDPE70 & 0.02818 & 0.08456 & 0.11275 & 0.14094 & 0.16913 \\
\hline 9 & HDPE100 & 0.041744 & 0.09822 & 0.12277 & 0.14733 & 0.14734 \\
\hline
\end{tabular}

\subsection{Wear loss with respect to the sliding speed}

Table 5 gives the values of volume loss as abrasion wear under different sliding speeds. The plotted values for volume loss against sliding speeds for the tested specimens is given as Fig. 12. The wear behavior for the specimens was found to influence with different sliding speeds. The wear of LDPE specimens increases with replacement at the sliding speed of $0.5388 \mathrm{~m} / \mathrm{s}$ whereas an analogous behavior is observed at the sliding speed of $0.8980 \mathrm{~m} / \mathrm{s}$. Moreover, the decrease in wear at the higher speed of $1.0776 \mathrm{~m} / \mathrm{s}$ is consistent as reported by the studies that wear is not influences by the load at the higher sliding speed [70-72]. It is observed that under the similar replacement of LDPE and HDPE by sand, the LDPE specimens show better wear resistance as compared to HDPE specimens the greater elasticity possess by the LDPE can be the possible cause for improvement. The minimum values for the volume losses at the condition of minimum and maximum sliding speeds i.e. 0.5388 and $1.4369(\mathrm{~m} / \mathrm{s})$ were found to be $0.3267 \mathrm{~cm}^{3}$ and $0.10292 \mathrm{~cm}^{3}$ for the composites as LDPE50 and LDPE60 respectively. It is also observed that at the sliding speeds of $0.71845 \mathrm{~m} / \mathrm{s}$ and $0.8980 \mathrm{~m} / \mathrm{s}$ the specimen LDPE100 is having minimum wear with equal volume loss of $0.05949 \mathrm{~cm}^{3}$. The absence of sand particles and elastic nature of the LDPE improves the toughness of the specimen and the visco-elastic effect plays a significant role in the reduction in wear within a moderate range of speed. Further, increasing the speed to $1.0776 \mathrm{~m} / \mathrm{s}$ the minimum value for wear was obtained to 0.03095 
$\mathrm{cm}^{3}$ for LDPE50PET20, the partial replacement of LDPE by PET and incorporation of sand bring down the ductility additionally the visco-elastic effect predominates at higher sliding speed.

Table 5

Abrasive wear at different sliding speed

\begin{tabular}{|lllllll|}
\hline S.N0 & Sample designation & \multicolumn{4}{l}{ Wear rate $\left(\mathrm{cm}^{3}\right)$ at sliding speeds } \\
\cline { 3 - 7 } & & $\mathbf{0 . 5 3 8 8} \mathbf{~} / \mathbf{s}$ & $\mathbf{0 . 7 1 8 4} \mathbf{~} / \mathbf{s}$ & $\mathbf{0 . 8 9 8 0} \mathbf{m} / \mathbf{s}$ & $\mathbf{1 . 0 7 7 6} \mathbf{~} / \mathbf{s}$ & $\mathbf{1 . 4 3 6 9} \mathbf{~} / \mathbf{s}$ \\
\hline 1 & LDPE50 & 0.03267 & 0.09801 & 0.13068 & 0.06534 & 0.16335 \\
\hline 2 & LDPE60 & 0.03430 & 0.06861 & 0.10292 & 0.06861 & 0.10292 \\
\hline 3 & LDPE70 & 0.04510 & 0.09021 & 0.09021 & 0.09021 & 0.13531 \\
\hline 4 & LDPE100 & 0.05949 & 0.05949 & 0.05949 & 0.05949 & 0.11898 \\
\hline 5 & HDPE50 & 0.09994 & 0.14991 & 0.14991 & 0.17490 & 0.29983 \\
\hline 6 & HDPE60 & 0.04864 & 0.09729 & 0.17027 & 0.12162 & 0.29191 \\
\hline 7 & HDPE70 & 0.08456 & 0.16913 & 0.19732 & 0.16913 & 0.31008 \\
\hline 8 & HDPE100 & 0.07366 & 0.14733 & 0.09822 & 0.12277 & 0.19644 \\
\hline 9 & LDPE50 PET20 & 0.09287 & 0.06191 & 0.12383 & 0.03095 & 0.21670 \\
\hline
\end{tabular}

It is observed that at low sliding speed i.e. $0.5388 \mathrm{~m} / \mathrm{s}$ the volume loss for the LDPE specimens increases with replacement as the sand particles were unable to penetrate into the surface especially for composites having a sufficient fraction of sand i.e. LDPE50 and HDPE50. In this case the abrasive primarily rubs over the specimen surface and causes less removal of material as debris. The comparative study for the individual specimen under the given different speeds showed the wear was maximum at the condition of maximum speed. However, the behavior was different for the lower speed of sliding. The wear rate increases with initial load from its lowest level for some of the specimens upto a certain limit after that a sharp decrease in the wear rate with loading is observed and the behaviors are quite similar to those reported in the earlier studies [73-75].

\section{Morphological Observation Of The Wear Surface}

The worn surfaces due to abrasion of the prepared composites were examined to probe the wear mechanism of the composites. The optical micrograph for the abraded surface under low loads and sliding speeds are given in Fig. 13 (a-h) which shows micro-plowing and micro-cutting with long furrows in the abrading direction as the dominating wear mechanism with significant differences with sand replacement were observed. Worn surfaces of the composite specimens with 50,60 , and 70 (wt. \%) as LDPE and HDPE are given in (Fig. 13a-c) and Fig. 13 (e-g) respectively that shows the presence of grooves and particles indicating cutting action.

The increase of fillers fraction makes the composite brittle and the cutting action dominates hence the specimens with $50 \%$ of sand shows excessive surface damage due to brittle nature and dominant cutting as 
wear mechanism. Also the unfilled specimens for LDPE and HDPE are ductile the material removal by plowing action is dominant [76]. Some interfacial deboning and fiber peeling off were observed over the worn surfaces as shown in Fig. 13 (a) and (e) and were not present over the worn surfaces of the neat LDPE and HDPE specimens as shown in Fig. 13 (d) and (h). This explains the reason for the significant lower wear resistance of LDPE50 and HDPE50 as compared to LDPE100 and HDPE100 respectively. Moreover, fiber breakage, fiber polishing, micro-plowing and micro-cutting of the matrix are the dominating wear mechanisms for the specimens even though few fiber-matrix interfacial deboning and fiber peeling off can be seen over the specimens with sand replacement. This explains why the wear rate of the specimens with different fraction of sand in a particular type of plastic is not substantially different from the specimen without sand at the condition of low loading and sliding speed.

The morphological features of the abraded surfaces changes with combinations of the encountering stress. The effects of plastic deformation and scratching were observed over the abraded surfaces. The surface layer is extruded and displaced in various ways and leaving scratches. The indentation and extrusion are the causes of plastic deformation. The occurrence of pile-up is due to compressive stress whereas plastic deformation is due to tensile stress which starts with the initiation of micro-cracks and propagates further. If the indentation is small then only plastic deformation occurs, additionally micro-plowing, and micro-cutting were observed over the abraded surface as shown in Fig. 14 (a-d). Moreover, in the three-body abrasive wear configuration the abrasive particles are free to roll as well as slide between the targeted specimen and the rotation rubber wheel. There exist a greater possibility for rolling of abrasive particle compared to sliding the predominant wear mechanism is plastic deformation due to multi-indentations. Due to the sliding motion of the abrading particles localized small grooves and fine scratches were observed Fig. 14 (a). The presence of characteristic wear debris as small particles may be attributed to the plowing and cutting action of the abrasive particles. Figure 14 (b) shows abrasion due to micro-cutting with additional plastic deformation. Figure 14 (c) shows predominant abrasive wear due to micro-cutting additionally under the conditions of high load and speed. Figure 14 (d) is characterized by abrasive wear with multiple particle indentations due to three-body abrasion. During abrasion the sand grit slides over the composites and generates debris. The debris plays an important role in the wear of composites as some of the debris stays at the contact zone and forms a transfer film while other debris escapes from the contact zone. The accumulation of debris increases with applied load and decreases with the increase of sliding speed. This would be the possible cause for reduction of wear at higher load as shown in Fig. 11. The softening with large wear debris appears due to the combined action of high load and high sliding speed causes a significant increase of the wear at the high sliding speed of $1.4369 \mathrm{~m} / \mathrm{s}$. The worn surface of the composites were significantly deteriorated with pitting as the predominant wear mechanism. As the load is increased deboning and delamination of the fibers looses the fibres and easily removed. Additionally at the conditions of low load and high-speed the sizes of the debris becomes larger and fibers seem to wash away which is associated with cracks, distorted grooves, and pitting in certain areas as shown in Fig. $15(a, b)$. The surface layer of material is plowed due to plastic deformation and ridges were pressed flat by the following particles. The large cavities indicate the peeling of the plastic fibers and weak interfacial bonding. The better interfacial bonding for the composites reduces the peeling of fibers. The poor interfacial strength reduces the wear resistance as reported in the earlier studies [77]. Further to elucidate the wear mechanism at the conditions of low $(34.335 \mathrm{~N})$ and high $(90.742 \mathrm{~N})$ loads morphologies study of the abraded surfaces was conducted. Worn surfaces of LDPE100 and HDPE100 under 
a low load of $34.335 \mathrm{~N}$ and a high load of $90.742 \mathrm{~N}$ are shown as Fig. 16 (a-b) and Fig. 17 (a-b) respectively. The analysis of the worn surfaces showed that under high loading condition the surface becomes smoother as the sand experiences more damage which diminish its capacity for penetration and plowing and the surfaces becomes rougher with craters under lower load implies that the abrasive sand is effective to penetrate the surface accompanied with larger damage. The latter was relatively smooth with fewer craters. It appears that the damage to the specimen by the low load is more than high load. During the abrasion at high speed the temperature at the contact surface increases with sliding distance which loses the bond and removes the material that is progressive with sliding distance. The composite has better wear resistance due to the micro-cutting mechanism whereas in pure polymer deep plowed grooves were observed.

Figures $18(a, b)-20(a, b)$ shows the wear mechanism with the progression of load. Micro-cutting and wedge formation due to micro plowing were observed as the main wear mechanism for the composites prepared. Fig. $18(a, b)$ the wear surfaces shows more proportion of scratches with plastic deformation at the edges (micro plowing mechanism) than scratches without plastic deformation (micro-cutting mechanism) [78] whereas in Fig. 20 (a, b) the contrary was observed and in Fig. 19 (a, b) no predominant wear mechanism was found. The increase in contact pressure with the normal load increases the proportions of micro-cutting moreover at low loads condition micro-cutting mechanism are replaced by micro plowing. The lesser degree of penetration at low loads is the possible cause of such translation of mechanism and is consistent with the results reported by Kitsunai et al. (1990) [79]. The high wear loss at high speed and load is accomplished due to excessive shear stress at the contact surface than the interfacial strength of the composites causing the fiber pull-out and peeling off. In other words, the wear resistance is influenced by interfacial strength at high speed and load due to deboning of fibers and severe force exerted by the grit, additionally some debris can be seen on the worn surface. The debris escapes the contact zone at high sliding speed and contributes to higher material loss.

\section{Conclusions}

The development of homogenous and hybrid plastics based composites along with the tribological investigation as abrasive wear for the developed plastics based composites under conditions of different applied loads as well as sliding speeds were carried out. Dry sand-rubber wheel abrasion tester is employed for the evaluation of volume loss as three-body abrasion. Wear mechanism and wear performance were found to significantly influence by the fraction of sand, applied load, and sliding speeds. The correlation was established between the wear and mechanical properties. Based on the experimental results and discussions the following major conclusions are drawn:

1. An enhancement in the wear resistance with reinforcement is noticed. Moreover, there exists a critical volume fraction above which the wear resistance decreases.

2. The optical microscopy of the worn surfaces of the tested composite sample indicates that removal of material during abrasion was mainly due to plastic deformation, micro ploughing, micro-cutting and crack mechanism preferably, in the binder by its extrusion and micro-cutting or ploughing. Also at the conditions of high load and speed fatigue pitting was evident. 
3. A good correlation was exist between the wear rate and combinations of mechanical properties. Furthermore, due to a wide range of composites with distinct composition and properties some anomalies were found.

4. The observation of resulted values of abrasive wear for LDPE and HDPE specimens under varying loads indicates that at the condition of low loads i.e. $34.335 \mathrm{~N}$ the minimum wear was shown by the specimens as LDPE100 and HDPE50 with volume loss of $0.023796 \mathrm{~cm}^{3}$ and $0.02498 \mathrm{~cm}^{3}$ respectively. However, at high loads condition i.e. $90.742 \mathrm{~N}$ specimens as LDPE50 and HDPE60 gives the minimum abrasive wear with volume loss of $0.03267 \mathrm{~cm}^{3}$ and $0.14594 \mathrm{~cm}^{3}$ respectively.

5. The results of abrasive wear for LDPE and HDPE specimens under sliding speeds indicates that at lower sliding speed i.e. $0.5388 \mathrm{~m} / \mathrm{s}$, the minimum wear was showed by the specimens as LDPE50 and HDPE60 with volume loss of $0.03267 \mathrm{~cm}^{3}$ and $0.04864 \mathrm{~cm}^{3}$ respectively. However, at high sliding speed i.e. $1.4369 \mathrm{~m} / \mathrm{s}$, the minimum wear was shown by the specimens as LDPE60 and HDPE100 with volume loss of $0.10292 \mathrm{~cm}^{3}$ and $0.19644 \mathrm{~cm}^{3}$ respectively.

6 . The overall result for the tested composite specimens within the given sliding speeds $(0.5388,0.7184$, $0.8980,1.0776$ and $1.4369 \mathrm{~m} / \mathrm{s}$ ) and loads (34.335, 56.898, 68.179, 79.461 and $90.742 \mathrm{~N}$ ) shows the minimum value of wear to be $0.02498 \mathrm{~cm}^{3}$ for the specimen as HDPE50 due to high density and sufficient strength of the composite.

7. The study suggests a throughout analysis of the microstructure with a corresponding wear mechanism for identifying the wear rate of materials.

\section{Declarations}

\section{Conflict of Interest}

The authors declare that they have no known competing financial interests or personal relationships that could have appeared to influence the work reported in this paper.

\section{References}

1. Holmberg K, Erdemir A (2017) Influence of tribology on global energy consumption, costs and emissions. Friction 5(3): 263-84.

2. Nosonovsky M, Bhushan B (2010) Green tribology: principles, research areas and challenges. Phil. Trans. R. Soc. A 368: 4677-4694. doi:10.1098/rsta.2010.0200

3. Zhang S W (2013) Green tribology: fundamentals and future development. Friction 1 (2):186-94.

4. Budinski K G, Budinski M K (2010) Engineering Materials: Properties and Selection, 9thEd. Upper Saddle River, NJ: Prentice Hall 114.

5. Garner H A (1982) Dry sand-rubber wheel abrasion wear testing of the carpenter matched tool and die steels. Lubr. Eng. 38 (6), 359-364.

6. Scholl M (1997) Abrasive wear of TiN coatings. Conf. on Wear of Materials. Wear 203-204: 57-64.

7. Swanson P A (1977) Comparison of laboratory and field abrasion tests, In: K.C. Ludema K C (ed) Proc. Int. Conf. On Wear of Materials, ASME, New York 148-157. 
8. Swanson P A (1983) Comparison of laboratory and field tests, In: Ruff A W, Buyer R G (ed) Tribology: Wear Test Selection for Design and Application, ASTM, Philadelphia, PA 80-99.

9. Blanchett T A, Kennedy F E (1989) The Development of Transfer Films in Ultra High Molecular Weight Polyethylene/Stainless Steel Oscillatory Sliding, Tribology Transactions 32: 371-379.

10. Warren J H, Eiss N S (1978) Depth of Penetration as a Predictor of the Wear of Polymers on Hard, Rough Surfaces. Transactions ASME, Journal of Lubrication Technology 100: 92-97.

11. Hutchings I M (1992) Tribology-Friction and Wear of Engineering Materials. Edward Arnold, London.

12. Bingley M S, Schnee S (2005) A study of the mechanisms of abrasive wear for ductile metals under wet and dry three-body conditions. Wear 258: 50-61. https://doi.org/10.1016/j.wear.2004.01.022

13. Wirojanupatump S, Shipway P H (1999) A direct comparison of wet and dry abrasion behaviour of mild steel. Wear 233-235: 655-665. https://doi.org/10.1016/S0043-1648(99)00208-2

14. Petrica M, Katsich C, Badisch E, Kremsner F (2013) Study of abrasive wear phenomena in dry and slurry 3-body conditions. Tribol. Int. 64: 196-203.

15. Garner H A (1982) Dry sand/rubber-wheel abrasion wear testing of the carpenter matched tool and die steels. Lubric. Eng. 38 (6): 359-364.

16. Gee MG, Owen - Jones S (1998) Wear Testing Methods and Their Relevance to Industrial Wear Problems. Centre for Materials Measurement and Technology National Physical Laboratory Queens Road, Teddington, Middlesex, TW11 OLW https://eprintspublications.npl.co.uk/3426/1/cmmt92.pdf

17. Brinell J A (1921) Researches on the resistance of iron, steel and some other materials to wear, Jernkontorets Ann. 76: 347-398.

18. Swanson P A (1977) Comparison of laboratory and field abrasion tests, In: Ludema KC (Ed.), Proceedings of the International Conference on Wear of Materials, ASME, New York 148-157.

19. Swanson P A (1983) Comparison of laboratory and field tests, in: A.W. Ruff, R.G. Buyer (Eds.), Tribology: Wear Test Selection for Design and Application, ASTM, Philadelphia, PA, 80-99.

20. Haworth Jr. R D (1949) Trans. ASM 41: 819-869.

21. Avery H S (1981) Proceedings of the International Conference on Wear of Materials, ASME, New York 367-378.

22. Misra A, Finnie I (1979) A classification of three-body abrasive wear and design of a new tester. In: Ludema K C, Glaeser W A, Rhee S K (ed) Wear of Materials. ASME, New York 313-318.

23. ASTM G65-94, Standard test method for measuring abrasion using the dry sand-rubber wheel apparatus. Annual Book of ASTM Standards, Vol. 03.02, ASTM, Philadelphia, PA, pp. 245-256.

24. 24.Stevenson A N J, Hutchings I M (1996) Development of the dry sand-rubber wheel abrasion test. Wear 195: 232. https://doi.org/10.1016/0043-1648(96)06965-7

25. Haworth Jr. R.D (1949) The abrasion resistance of metals, Trans. ASM 41: 819-869.

26. Avery H S (1981) An analysis of the rubber wheel abrasion test. In: Rhee S K, Ruff A W, Ludema K C (ed) Proc. Int. Conf. On Wear of Materials, ASME, New York 367-378.

27. Shangguan Q, Cheng X (2007) Friction and wear of rare earths modified carbon fibers filled PTFE composite under dry sliding condition. Appl. Surf. Sci. 253 (22): 9000-06. 
28. Liu P, Lu R, Huang T, Cong, P (2012) Tensile and tribological properties of polytetrafluoroethylene homocomposites, Wear $289: 65-72$.

29. Tanaka K, Kawakami S (1982) Effect of various fillers on the friction and wear of polytetrafluoroethylenebased composites. Wear 79(2): 221-34. https://doi.org/10.1016/0043-1648(82)90170-3

30. Tewari U S, Bijwe J (1991) Comparative studies on sliding wear of polyimide composites. Composites. 22(3):204-10.

31. Zhao G, Hussainova I, Antonov M, Wang Q, Wang T (2013) Friction and wear of fiber reinforced polyimide composites. Wear 301(1):122-9. https://doi.org/10.1016/j.wear.2012.12.019

32. Su F H , Zhang Z Z , Liu W M (2008) Tribological behavior of hybrid glass/PTFE fabric composites with phenolic resin binder and nano-TiO2 filler. Wear 264 (7-8):562-570.

https://doi.org/10.1016/j.wear.2007.04.007

33. Lancaster J K, Bay R G (1982) Selecting and Use of Wear Tests for Coatings, ASTM, STP.

34. Craig W D (1964) PTFE bearings. Lubr. Eng. 20 (12): 456-462.

35. Khedkar J, Negulescu I, Meletis E I (2002) Sliding wear behavior of PTFE composites. Wear 252 (5-6): 361-369. https://doi.org/10.1016/S0043-1648(01)00859-6

36. Li J , Ran Y (2010) Evaluation of the friction and wear properties of PTFE composites filled with glass and carbon fibre. Mater. Sci. Eng. Tech. 41: 115-118.

37. Rao M, Hooke C J, Kukureka S N, Liao P, Chen Y K (1998) The effect of PTFE on the friction and wear behavior of polymers in rolling-sliding contact, Polym. Eng. Sci. 38 (12): 1946-1958. https://doi.org/10.1002/pen.10364

38. Conte M, Igartua A (2012) Study of PTFE composites tribological behavior. Wear 296 (1-2): 568-574. https://doi.org/10.1016/j.wear.2012.08.015

39. Dhanumalayan E, Joshi GM (2018) Performance properties and applications of polytetrafluoroethylene (PTFE)-a review. Adv. Compos. Hybrid Mater. 1 (2): 247-268.

40. Cho J, Joshi M S, Sun C T (2006) Effect of inclusion size on mechanical properties of polymeric composites with micro and nano particles. Compos Sci Technol 66 (13): 1941-52.

41. Gurgen S (2019) Wear performance of UHMWPE based composites including nano-sized fumed silica. Compos B Eng. 173:106967.

42. Sharma S, Bijwe J, Panier S, Sharma M (2015) Abrasive wear performance of SiC-UHMWPE nanocomposites-Influence of amount and size. Wear 332: 863-71. https://doi.org/10.1016/j.wear.2015.01.012

43. Palabiyik M, Bahadur S (2002) Tribological studies of polyamide 6 and high-density polyethylene blends filled with PTFE and copper oxide and reinforced with short glass fibers. Wear 253(3-4): 369-76. https://doi.org/10.1016/S0043-1648(02)00144-8

44. Xian G, Zhang Z (2005) Sliding wear of polyetherimide matrix composites: I. Influence of short carbon fibre reinforcement. Wear 258(5-6):776-82. https://doi.org/10.1016/j.wear.2004.09.054

45. Peng Z, Xiao W, Xiao-dong W, Pei H, Jun S (2006) Tribology performances of molybdenum disulfide reinforced thermoplastic polyimide under dry and water lubrication conditions. Ind Lubric Tribol. 58(4):195-201. 
46. Lv M, Zheng F, Wang Q, Wang T, Liang Y (2015) Friction and wear behaviors of carbon and aramid fibers reinforced polyimide composites in simulated space environment. Tribol Int. 92: 246-54.

47. Shalwan A, Yousif B F (2013) In state of art: mechanical and tribological behaviour of polymeric composites based on natural fibres. Mater Des. 48: 14-24.

48. Shi Y, Feng X, Wang H, Lu X (2008) The effect of surface modification on the friction and wear behavior of carbon nanofiber-filled PTFE composites, Wear 264 (11-12): 934-939.

49. Tanaka K (1986) Effects of various fillers on the friction and wear of PTFE-based composites. Compos. Mater. 1: 137-174.

50. Su F H, Zhang Z Z, Liu W M (2005) Study on the friction and wear properties of glass fabric composites filled with nano-and micro-particles under different conditions, Mater. Sci. Eng., A 392: 359-365.

51. Gheisari R, Polycarpou A A (2019) Tribological performance of graphite-filled polyimide and PTFE composites in oil-lubricated three-body abrasive conditions. Wear 436-437: 1-11.

https://doi.org/10.1016/j.wear.2019.203044

52. Gu D P, Duan C S , Fan B L , Chen S W , Yang Y L (2016) Tribological properties of hybrid PTFE/Kevlar fabric composite in vacuum. Tribol. Int. 103: 423-431.

53. Cheng X H, Xue Y J , Xie C Y (2002) Friction and wear of rare-earth modified glass-fibre filled PTFE composites in dry reciprocating sliding motion with impact loads. Wear 253 (7): 869-877.

54. Sampath K P, Seetharamu S, Murali A, Kumar R K (1999) Dry sliding wear behaviour of glass-epoxy composite. J. Reinforc. Plast. Compos. 18 (1): 55-62.

55. Suresha B , Chandramohan G, Seetharamu S, Vynatheya S (2006) Friction and wear characteristics of carbon-epoxy and glass-epoxy woven roving fibre composites. J. Reinforc. Plast. Compos. 25 (7): 771 882.

56. Suresha B , Rao P R S, Chandramohan G (2007) Influence of SiC filler on mechanical and tribological behaviour of glass fabric reinforced epoxy composite systems, J. Reinforc. Plast. Compos. 26 (6): 565578.

57. Suresha B, Chandramohan G (2008) Three-body abrasive wear behaviour of particulate-filled glass-vinyl ester composites. J. Mater. Process. Technol. 200: 306-311.

58. Harsha AP, Tewari US (2007) Tribological studies on glass fibre reinforced polyether ketone composites. J. Reinforc. Plast. Compos. 23 (1): 65-82.

59. Besnea A, Trufasu D, Andrei G, Deleanu L (2012) Wear behaviour of polyphenylene sulphide composites during dry sliding tests. Mechl. Test. Diagn. 2: 15-20.

60. Yousif B F, El-Tayeb NSM (2009) Mechanical and wear properties of oil palm and glass fibre reinforced polyester composites, Int. J. Precis. Technol. 1 (2): 213-220.

61. Standard test method for measuring abrasion using the dry sand/rubber wheel Apparatus. ASTM standards, G65-04, 2004.

62. Suery M, Lajoye L (1990) Microstructural characterization of Al-Si/SiC composites, In: Rohatgi P (Ed.), Solidification of Metal Matrix Composites. The Minerals Metals and Materials Society.

63. Stevenson A N J, Hutchings I M (1996) Development of the dry sand rubber wheel abrasion test. Wear 195: 232-240. https://doi.org/10.1016/0043-1648(96)06965-7

Page $16 / 34$ 
64. Mirmohseni A, Zavareh S (2010) Preparation and characterization of an epoxy nanocomposites toughened by a combination of thermoplastic, layered and particulate nano-fillers. Materials and Design 31: 2699-2706.

65. Ha S R, Rhee K Y, Shin H J (2008) Effect of MMT Concentration on Tribological Behavior of MMT/Epoxy Nano composite. J Nanosci Nanotechnol 8(9): 4869-72.

66. Lingaraju D, Ramji K, Devi M P , Lakshmi U R (2011) Mechanical and Tribological Studies of Polymer Hybrid Nanocomposites with Nano Reinforcements. Bu. Mat. Sci. 34: 705-712.

67. Chisholm N, Mahfuzi H, Rangari V, Rodgers R, Jeelani S (2004) Synthesis and mechanical characterization of carbon/epoxy composites reinforced with SiC nano particles. NSTI Nanotech 3:302307.

68. Chand N, Naik A, Neogi S (2000) Three-body abrasive wear of short glass fibre polyester composite. Wear 242(1-2):38-46. https://doi.org/10.1016/S0043-1648(00)00398-7

69. Azwa Z N , Yousif B F , Manalo A C , Karunasena W (2013) Mater Des. 47: 424-442.

70. Fowler G, Pashby I R, Shipway P H (2009) The effect of particle hardness and shape when abrasive water jet milling titanium alloy Ti6Al4V.Wear 266 (7-8):613-20.

https://doi.org/10.1016/j.wear.2008.06.013

71. Harsha, A P, Tewari US (2003) Two-body and three-body abrasive wear behaviour of polyaryletherketone composites, Polymer Testing 22(4): 403-18.

72. Harsha AP, Tewari US, Venkatraman B (2003) Three-body abrasive wear behaviour of polyaryletherketone composites. Wear 254 (7-8): 680-92. https://doi.org/10.1016/S0043-1648(03)00142-X

73. Trezona R I , Hutchings I M (1999) Three-body abrasive wear testing of soft materials. Wear 233-235: 209-221. https://doi.org/10.1016/S0043-1648(99)00183-0

74. Allsopp D N, Trezona R I, Hutchings I M (1998) The effects of ball surface condition in the micro-scale abrasive wear test, Tribol. Lett. 5: 259-264. https://doi.org/10.1023/A:1019178716408

75. Shipway $\mathrm{PH}$, Hodge CJ B (2000) Micro abrasion of glass-the critical role of ridge formation. Wear 237: 90-97. https://doi.org/10.1016/S0043-1648(99)00309-9

76. Alam K I, Baratz A, Burris D (2021) Levering trace to engineer ultra-low wear polymer surfaces. Wear 482483: 203965. https://doi.org/10.1016/j.wear.2021.203965

77. Li W B, Haung J F, Fei J, Cao L Y, Yao CY (2015) Mechanical and wet tribological properties of carbon fabric/phenolic composites with different weave filaments counts, Appl. Surf. Sci. 35: 1223-1233.

78. Coronado JJ, Sinatora A (2011) Effect of abrasive size on wear of metallic materials and its relationship with microchips morphology and wear micro mechanisms: Part 1. Wear 271 (9-10): 1794-1803.

79. Kitsunai H , Kato K, Hokkirigawa K, Inoue H (1990) The transitions between microscopic wear modes during repeated sliding friction observed by a scanning electron microscope tribosystem. Wear 135 (2): 237-249.

80. Rabinowicz E, Mutis A (1965) Effect of abrasive particle size on wear. Wear 8: 381-390.

81. Zhang H., Zhang, H, Zhou L, Eger C, Zhang Z (2013) Abrasive wear of transparent polymer coatings: Considered in terms of morphology and surface modification of nanoparticles. Composites Science and Technology 88: 151-157. http://dx.doi.org/10.1016/j.compscitech.2013.08.024 
82. Zambrano O A, Aguilar Y, Valdes J, Rodriguez SA, Coronado J J (2015) Effect of Normal Load on Abrasive Wear Resistance and Wear Micromechanisms in FeMnAIC Alloy and other Austenitic Steels. Wear 348-349: 61-68. http://dx.doi.org/10.1016/j.wear.2015.11.019

83. Yousif B F, El-Tayeb N S M (2010) Wear characteristics of thermoset composite under high stress threebody abrasive. Tribology International 43: 2365-2371.

84. Xiong X, Shend S Z, Alamd N, Xiang Lid L H, Wan X, Miao M (2018) Mechanical and abrasive wear performance of woven flax fabric/ polyoxymethylene composites. Wear 414-415: 9-20. https://doi.org/10.1016/j.wear.2018.07.010

85. Woldman M , Van der Heide E, Schipper D J , Tinga T, Masen M A (2012) Investigating the influence of sand particle properties on abrasive wear behaviour. Wear. 294-295: 419-426.

http://dx.doi.org/10.1016/j.wear.2012.07.017

86. Wirojanupatump S, Shipway PH (2000) Abrasion of mild steel in wet and dry conditions with the rubber and steel wheel abrasion apparatus. Wear 239: 91-101. https://doi.org/10.1016/S0043-1648(00)00310-0

87. Tonga J, Maa Y, Arnellb R D, Rena L (2006) Free abrasive wear behavior of UHMWPE composites filled with wollastonite fibers , Composites: Part A 37: 38-45. doi:10.1016/j.compositesa.2005.05.023

88. Suresha B , Kunigal N, Kumar S (2009) Investigations on mechanical and two-body abrasive wear behaviour of glass/carbon fabric reinforced vinyl ester composites. Materials and Design 30: 2056-2060.

89. Srinath G, Gnanamoorthy R (2006) Two-body abrasive wear characteristics of Nylon clay nanocomposites-effect of grit size, load, and sliding velocity. Materials Science and Engineering A 435436: 181-186. doi:10.1016/j.msea.2006.07.117

90. Shipway P H, Ngao N K (2003) Microscale abrasive wear of polymeric materials, Wear 255 : 742-750. doi:10.1016/S0043-1648(03)00106-6

91. Xue Shen M, Dong F, Zhang Z , Kai Meng X, Peng X (2016) Effect of abrasive size on friction and wear characteristics of nitrile butadiene rubber (NBR) in two-body abrasion. Tribology International 103: 1-11. http://dx.doi.org/10.1016/j.triboint.2016.06.025

92. Petrica M , Katsich C , Badisch E , Kremsner F (2013) Study of abrasive wear phenomena in dry and slurry 3-body conditions, Study of abrasive wear phenomena in dry and slurry 3-body conditions. Tribology International 64: 196-203. http://dx.doi.org/10.1016/j.triboint.2013.03.028

93. Perfetti G, Depypere F, Zafari S, Van Hee P, Wildeboer WJ , Meesters GM H (2012) Attrition and abrasion resistance of particles coated with pre-mixed polymer coating systems. Powder Technology 230: 1-13. doi:10.1016/j.powtec.2012.04.009

94. Molnar W, Varga M, Braun P, Adam K, Badisch E (2014) Correlation of rubber based conveyor belt properties and abrasive wear rates under 2- and 3-body conditions. Wear 320: 1-6. http://dx.doi.org/10.1016/j.wear.2014.08.007

95. Ma X, Liu R , Li D Y (2000) Abrasive wear behavior of D2 tool steel with respect to load and sliding speed under dry sand-rubber wheel abrasion condition. Wear 241:79-85. https://doi.org/10.1016/S00431648(00)00351-3

96. Alessandra de A, Jose Ambrosio DL , Otaguro H, Lidiane Costa C , Jose Agnelli A M (2011) Abrasive wear of HDPE/UHMWPE blends. Wear 270: 576-583. doi:10.1016/j.wear.2011.01.011

Page $18 / 34$ 
97. Liu C, Ren L, Arnell R D, Tong J (1999) Abrasive wear behavior of particle reinforced ultrahigh molecular weight polyethylene composites. Wear 225-229: 199-204. https://doi.org/10.1016/S00431648(99)00011-3

98. Jia X , Ling R (2007) Two-body free-abrasive wear of polyethylene, nylon1010, expoxy and polyurethane coatings. Tribology International 40: 1276-1283. doi:10.1016/j.triboint.2007.02.013

99. Hyttel M W, Olsson D D , Reisel G , Bottiger J (2017) Comparison of a newly developed compression-twist abrasive wear test with the ASTM G65 test method. Wear 307, 134-141. http://dx.doi.org/10.1016/j.wear.2013.08.023

100. Harsha A P , Tewari U S, Venkatraman B (2003) Three-body abrasive wear behaviour of polyaryletherketone composites. Wear 254: 680-692. Doi: 10.1016/S0043-1648(03)00142-X

101. Bhanu K, Goriparthi K N S, Suman Rao N M (2012) Effect of fiber surface treatments on mechanical and abrasive wear performance of polylactide/jute composites. Composites: Part A 43: 1800-1808. http://dx.doi.org/10.1016/j.compositesa.2012.05.007

102. Elleuch K, Mezlini S, Guermazi N, Ph. Kapsa (2006) Abrasive wear of aluminium alloys rubbed against sand. Wear 261: 1316-1321. doi:10.1016/j.wear.2006.03.016

103. Coronado J J , Sinatora A (2009) Load effect in abrasive wear mechanism of cast iron with graphite and cementite. Wear 267: 6-11. doi:10.1016/j.wear.2008.12.071

104. Al-Rubaie S K, Goldenstein H, Biasoli de Mello J D (1999) Three-body abrasion of Al-SiC composites. Wear 225-229:163-173.

\section{Figures}

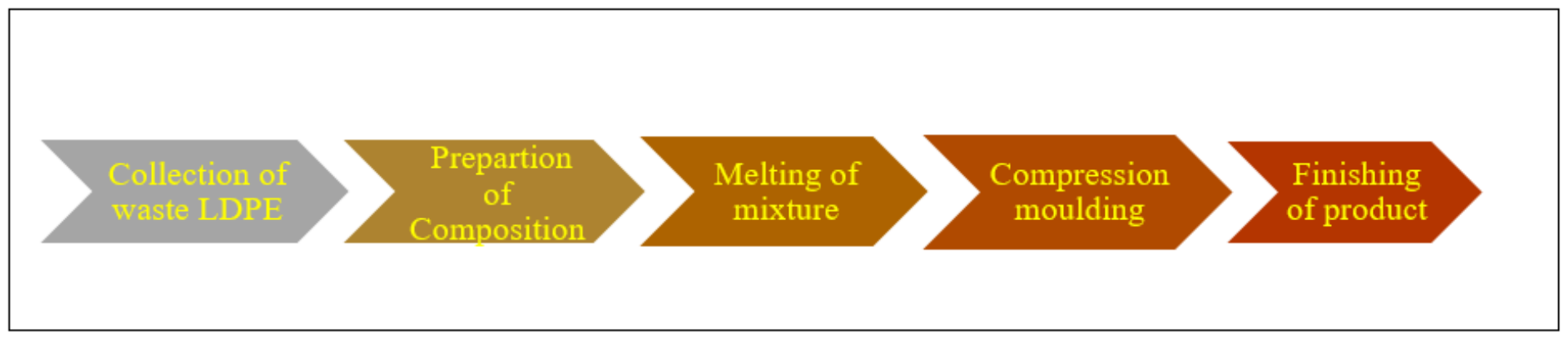

Figure 1

Process flow chart for specimens preparation 


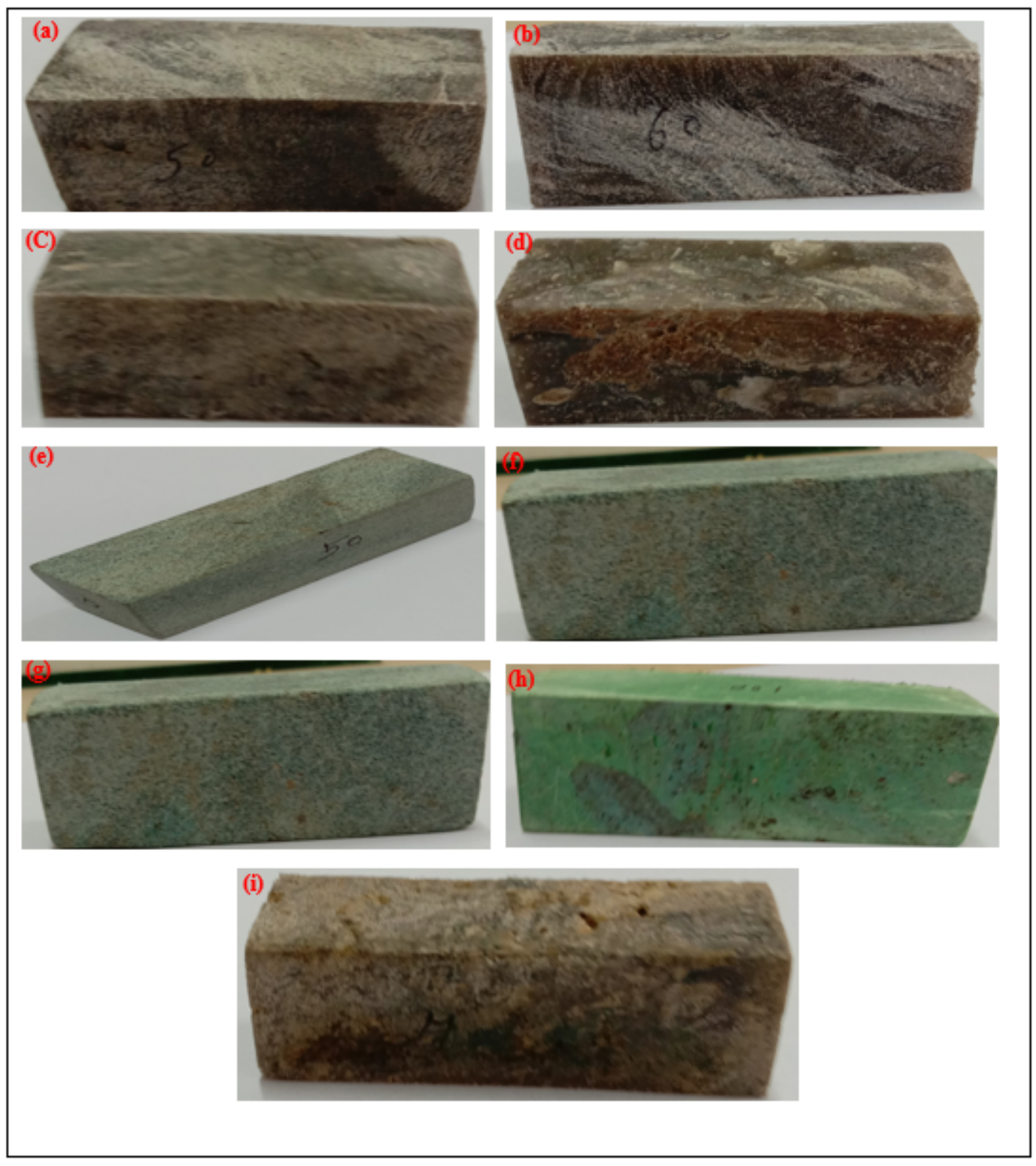

Figure 2

Specimens prepared for abrasive wear test (a) LDPE50 (b) LDPE60 (c) LDPE 70 (d) LDPE100 (e) HDPE50 (f) HDPE60 (g) HDPE70 (h) HDPE100 (i) LDPE50PET20 


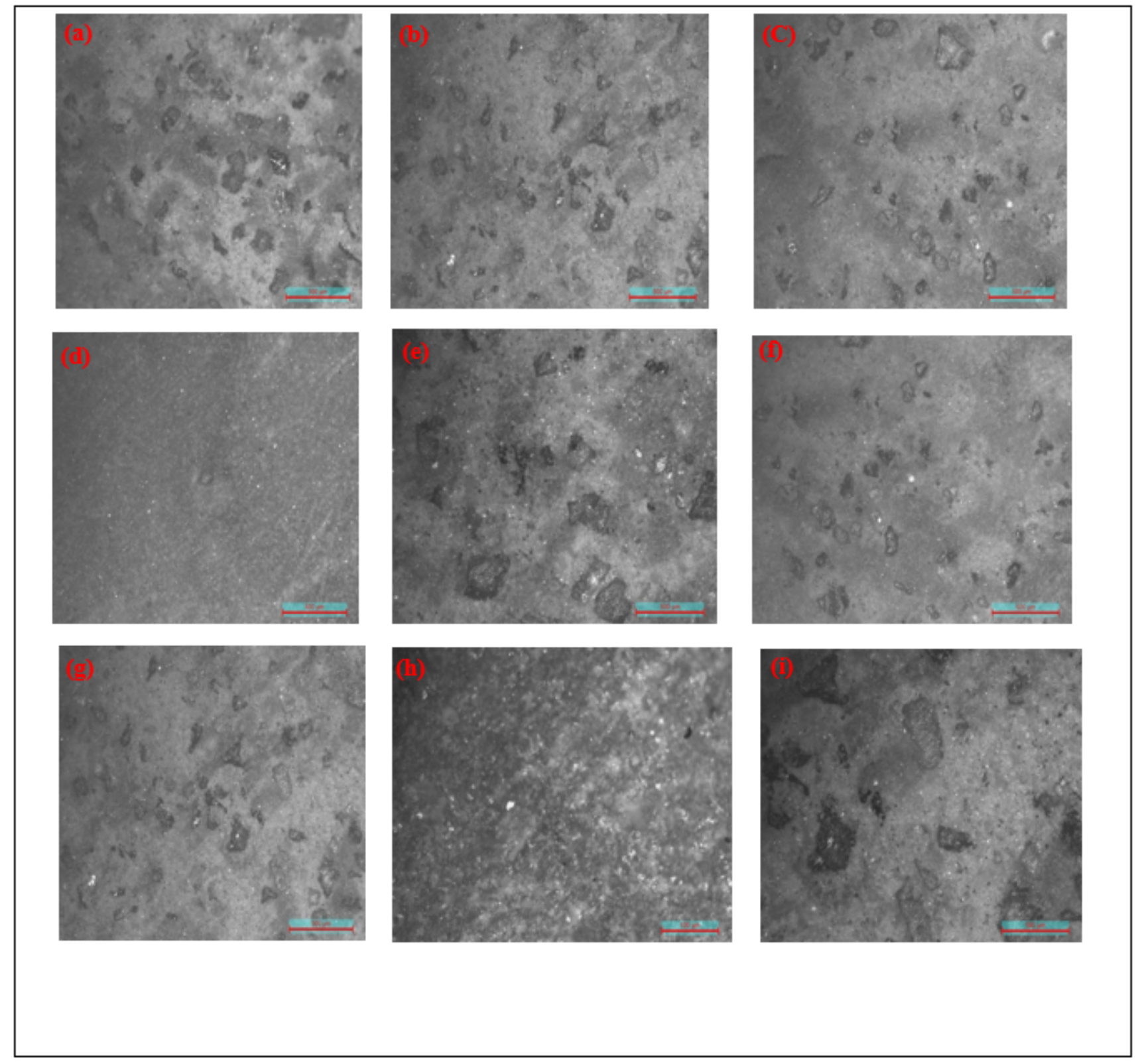

Figure 3

Optical micrographs of the sand- plastic composites surface (a) LDPE50 (b) LDPE60 (c) LDPE70 (d) LDPE100 (e) HDPE50 (f) HDPE60 (g) HDPE70 (h) HDPE100 (i) LDPE 50PET20 


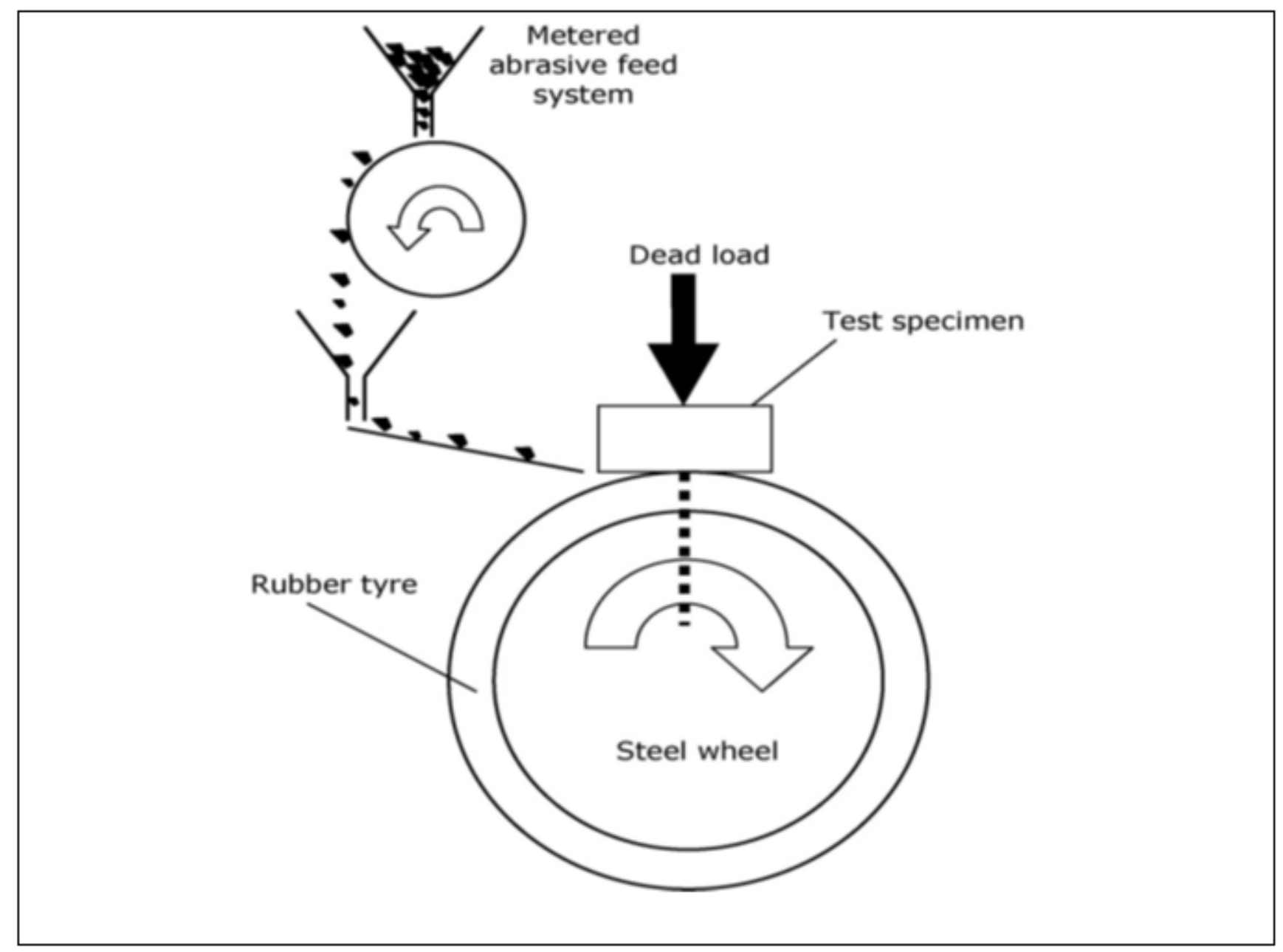

Figure 4

Schematic illustration of a rubber wheel abrasion testing apparatus 


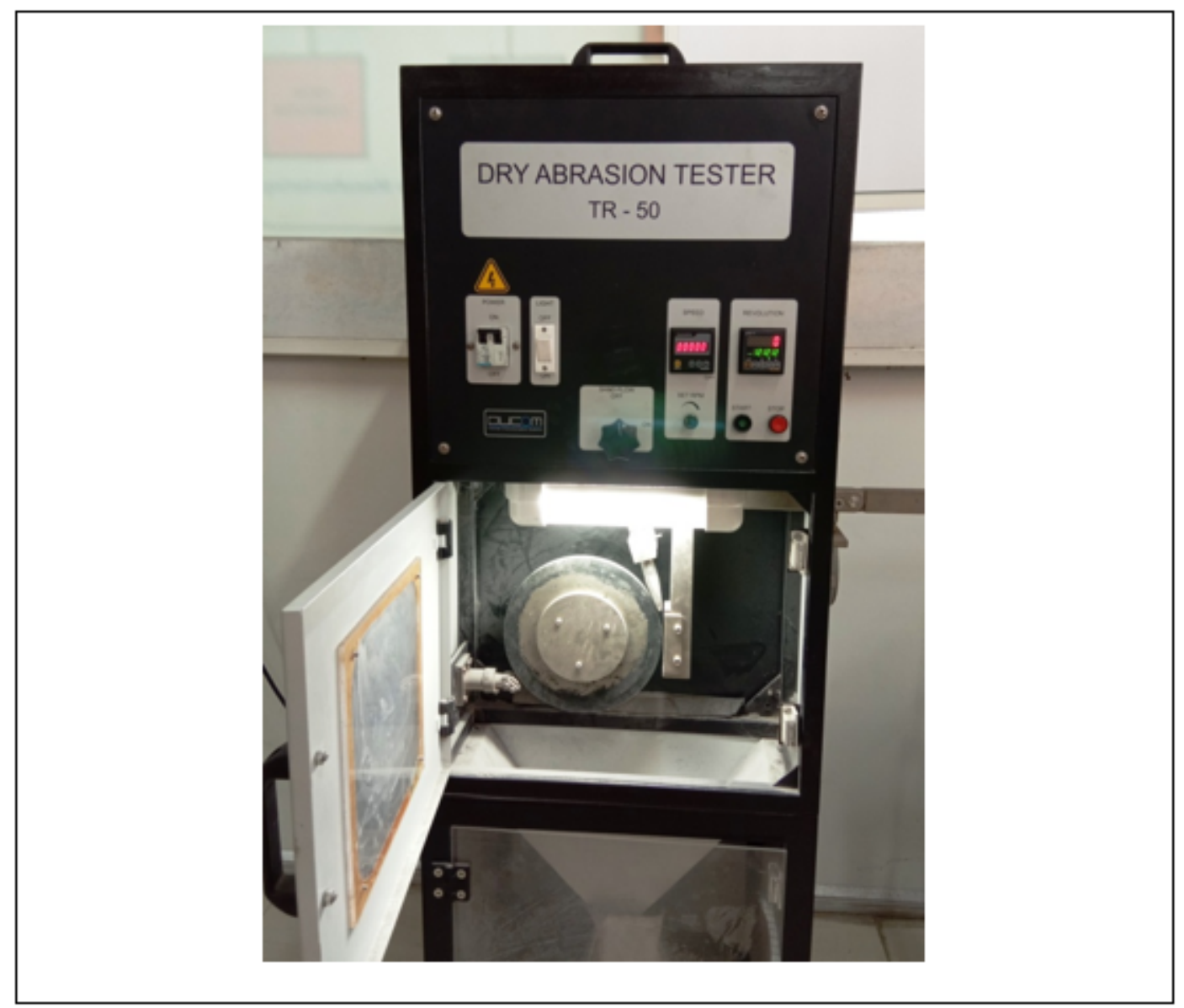

Figure 5

Dry Abrasion Tester TR-50

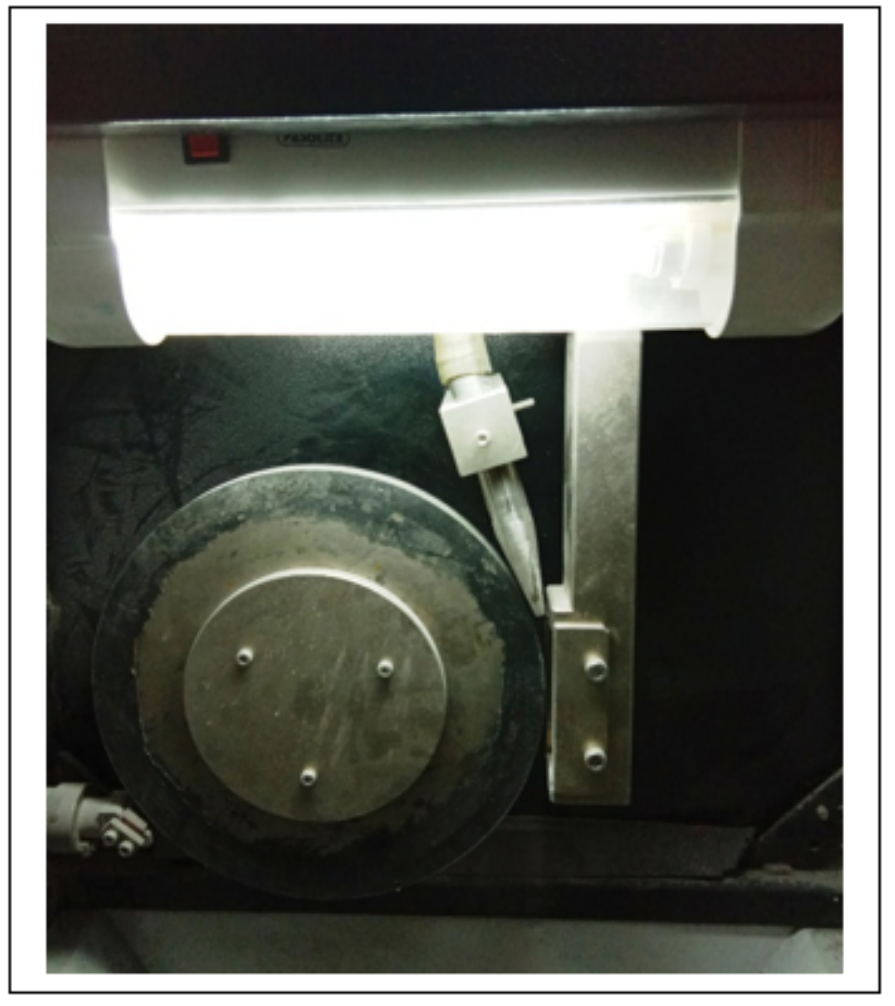


Figure 6

Specimen holder of Dry Abrasion Tester TR -50

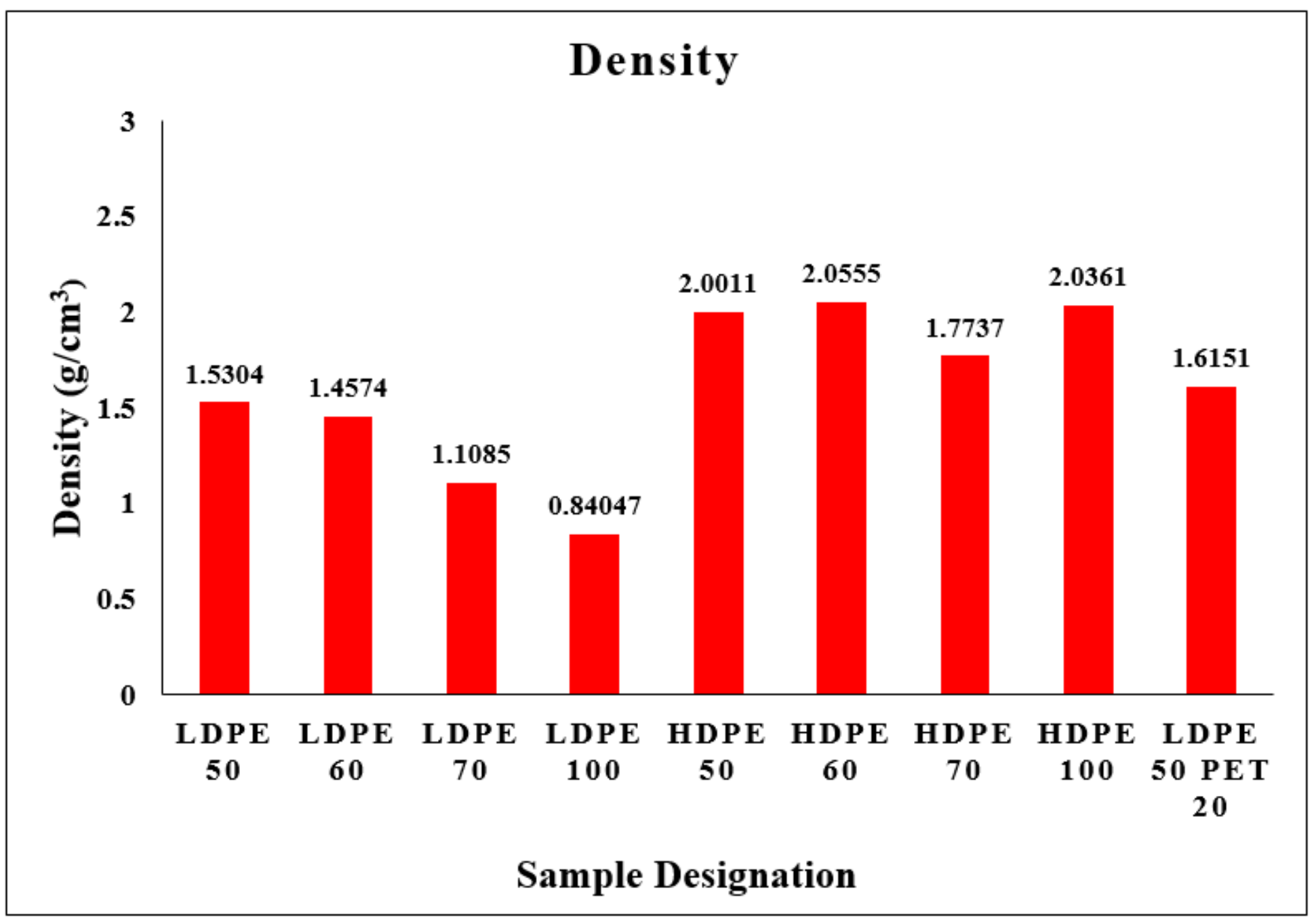

Figure 7

Density of the prepared specimens 


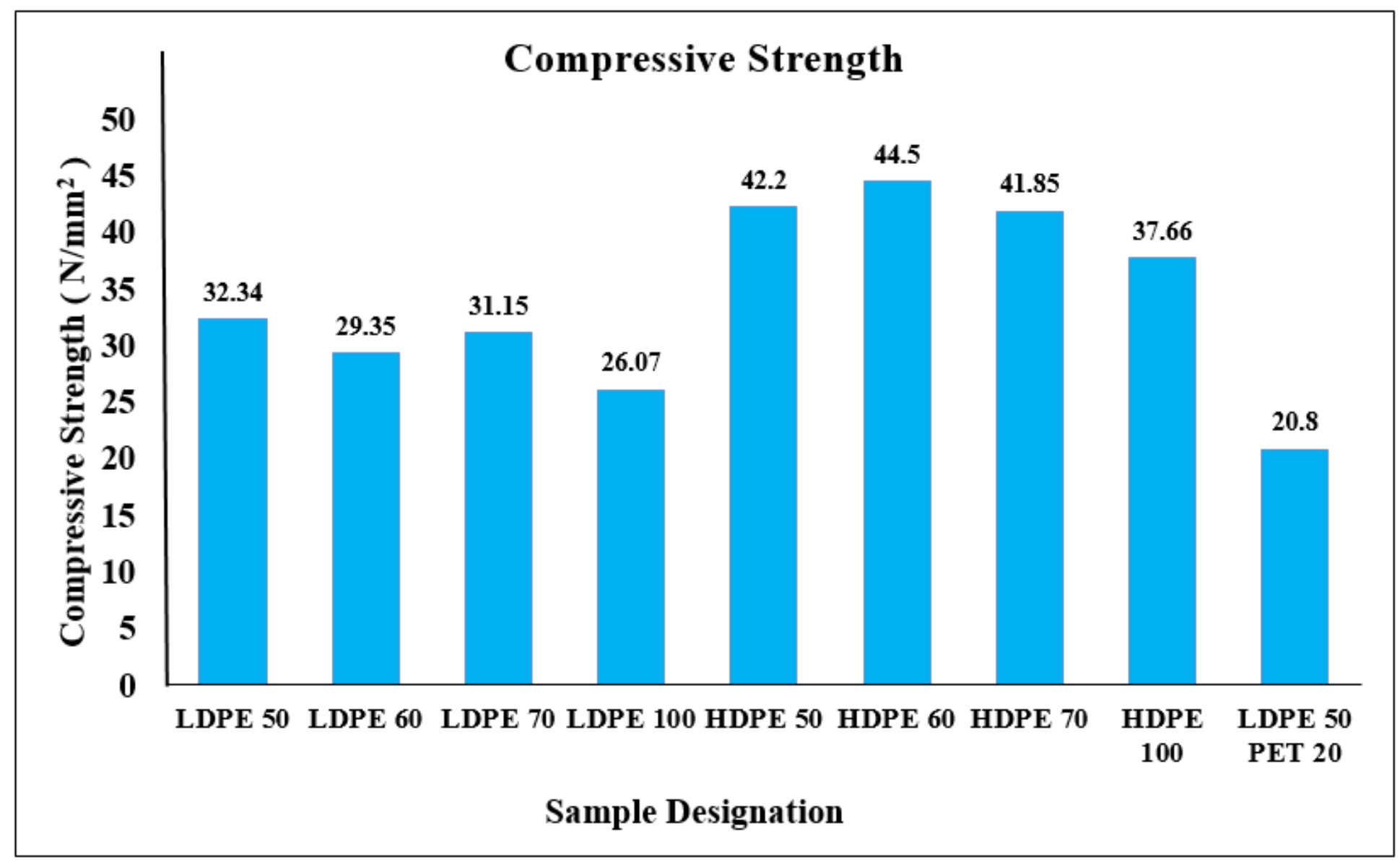

Figure 8

Compressive strength of the prepared specimens 


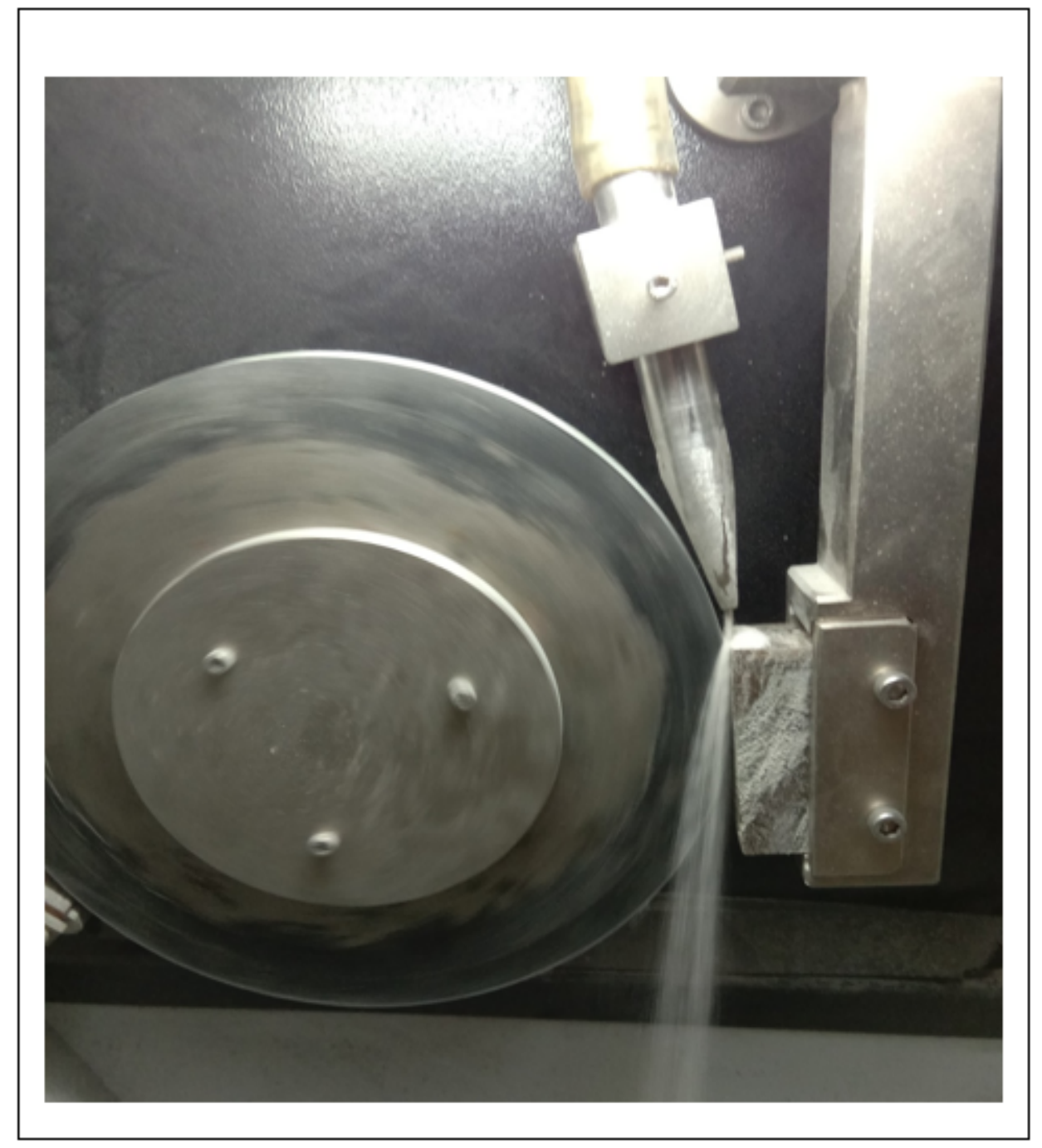

Figure 9

Specimen during wear 


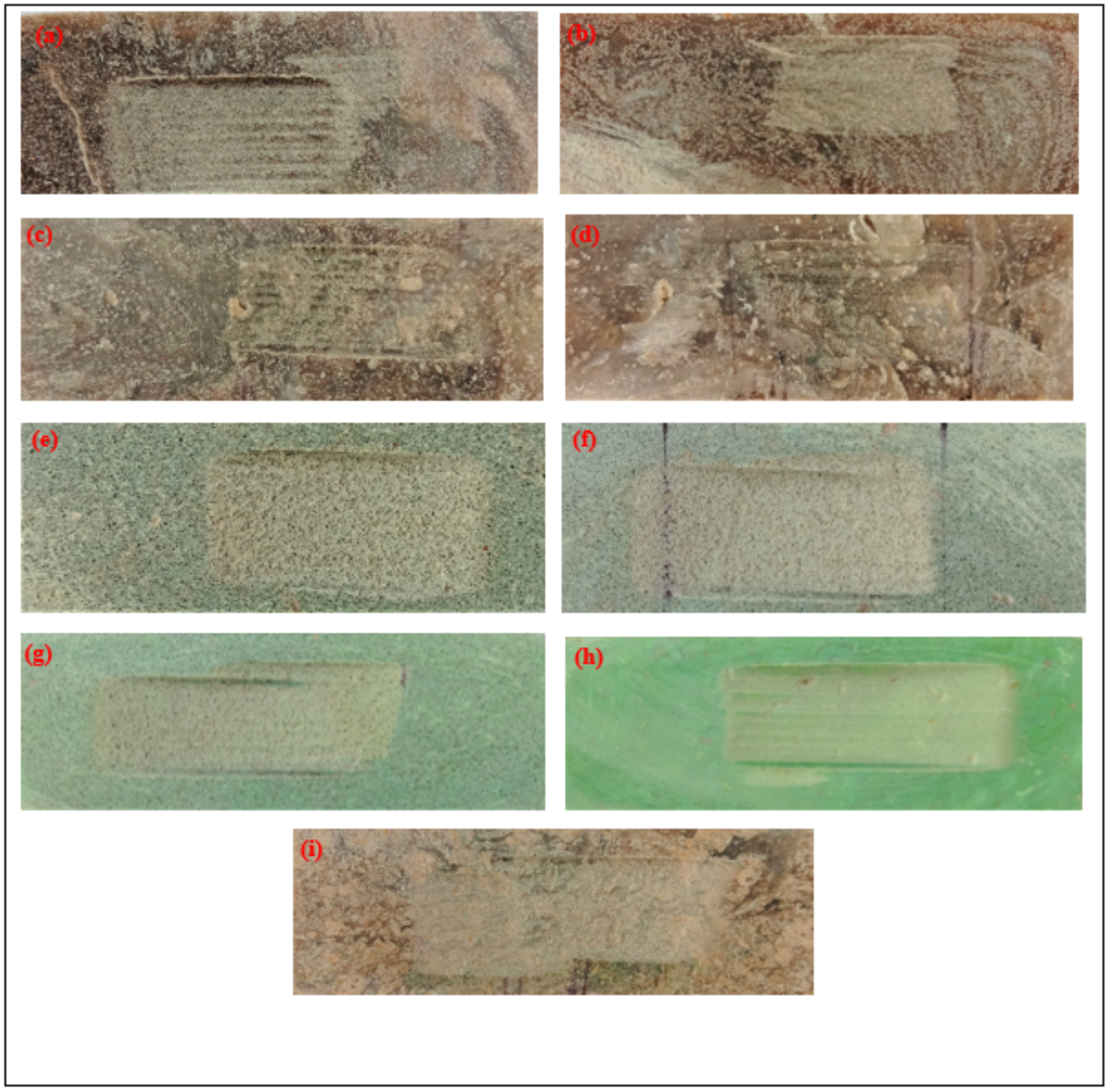

\section{Figure 10}

Images for wear scars of the sand- plastic composites (a) LDPE50 (b) LDPE 60 (c) LDPE70 (d) LDPE100 (e) HDPE50 (f) HDPE60 (g) HDPE70 (h) HDPE100 (i) LDPE 50PET20 


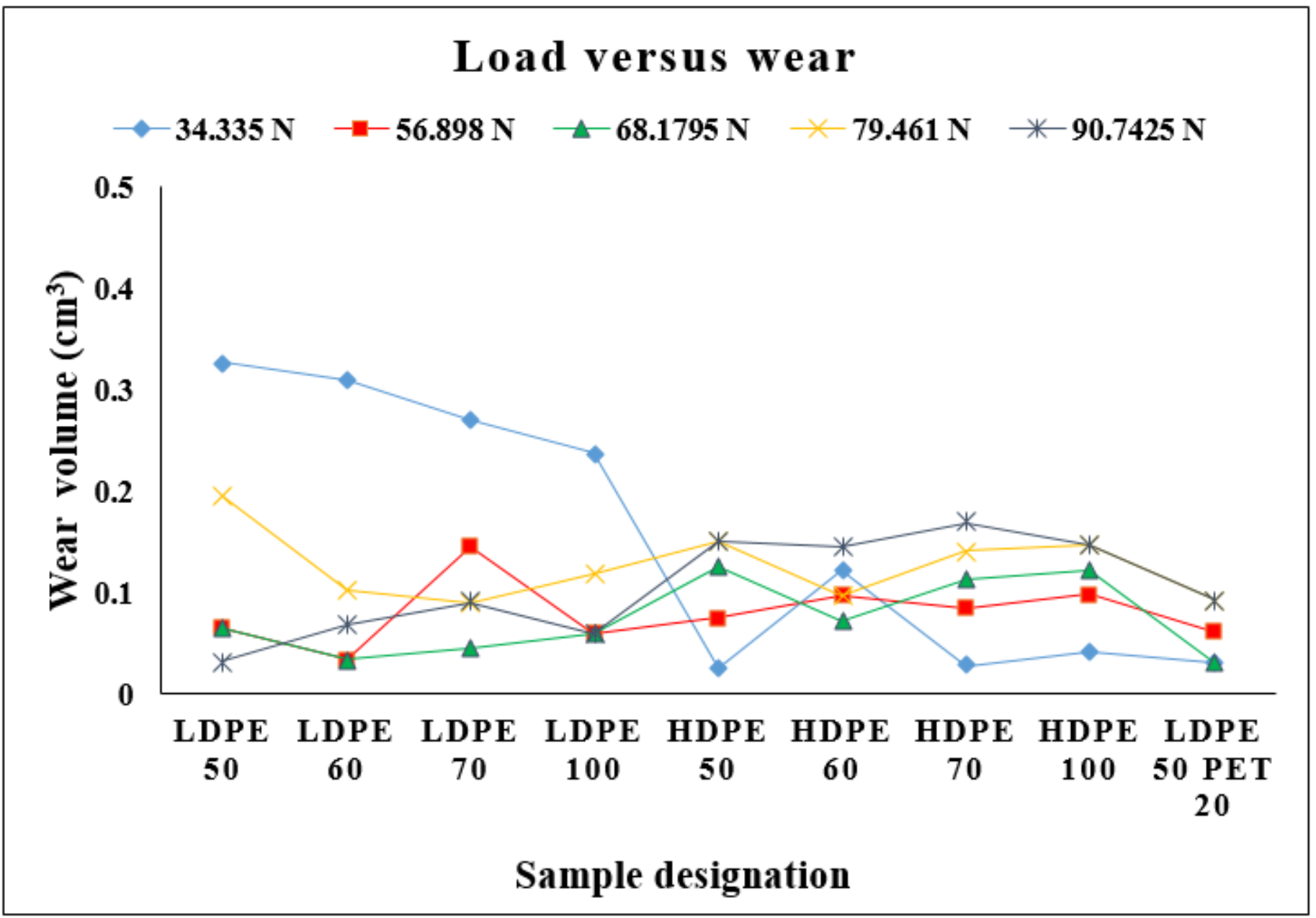

Figure 11

Wear of the specimens at different loading 


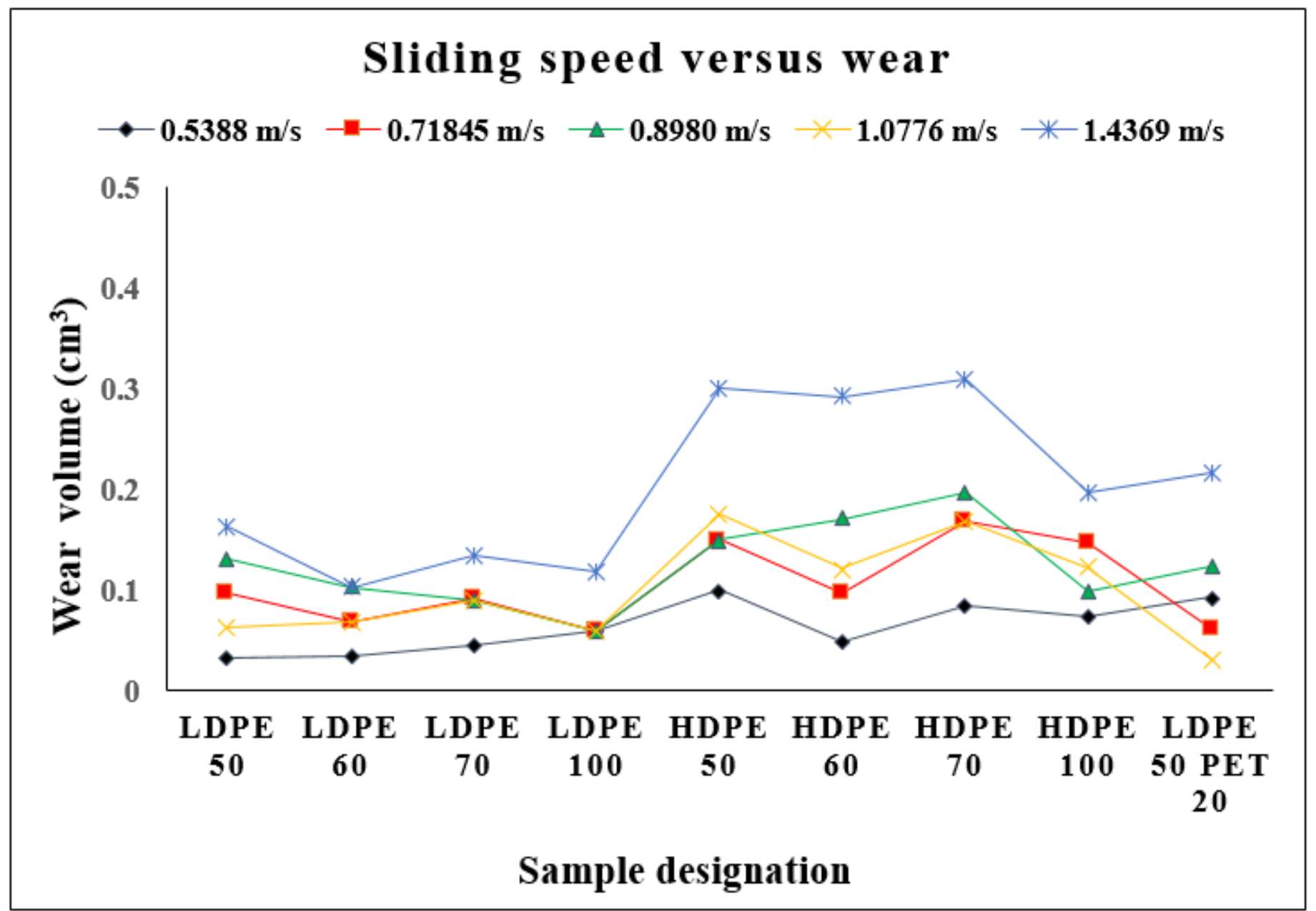

Figure 12

Wear of the specimens at different sliding speeds 


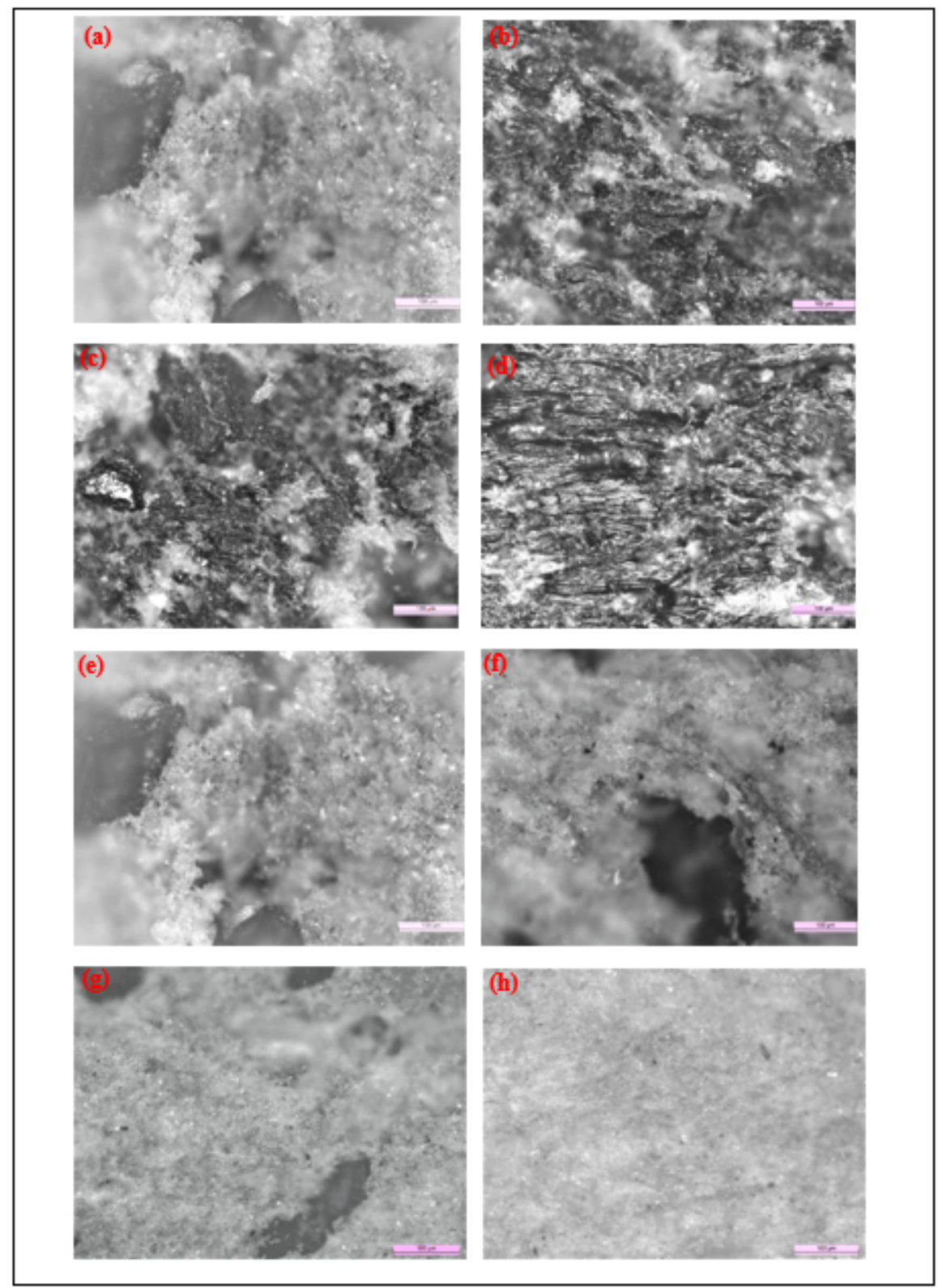

Figure 13

Optical microscopic images of specimens at $0.3592 \mathrm{~m} / \mathrm{s}$ and $34.335 \mathrm{~N}$ (a) LDPE 50 (b) LDPE60 (c) LDPE70 (d) LDPE100 (e) HDPE50 (f) HDPE60 (g) HDPE70 (h) HDPE100 


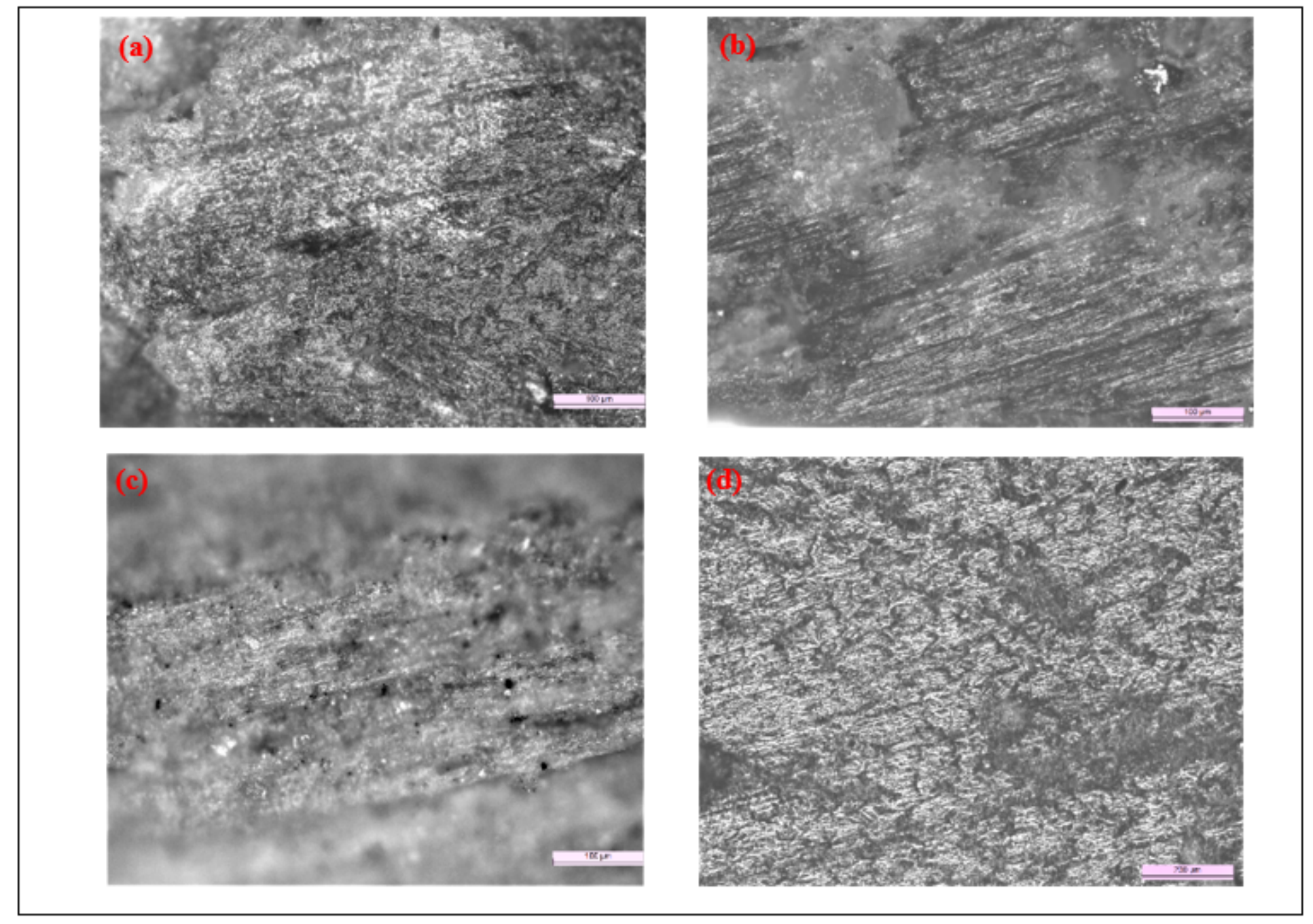

\section{Figure 14}

Optical microscopic images of specimens at sliding speed of $0.3592 \mathrm{~m} / \mathrm{s}$ (a) LDPE50PET20 (b) LDPE60 (c) HDPE100 (d) LDPE100 at speed $0.0980 \mathrm{~m} / \mathrm{s}$
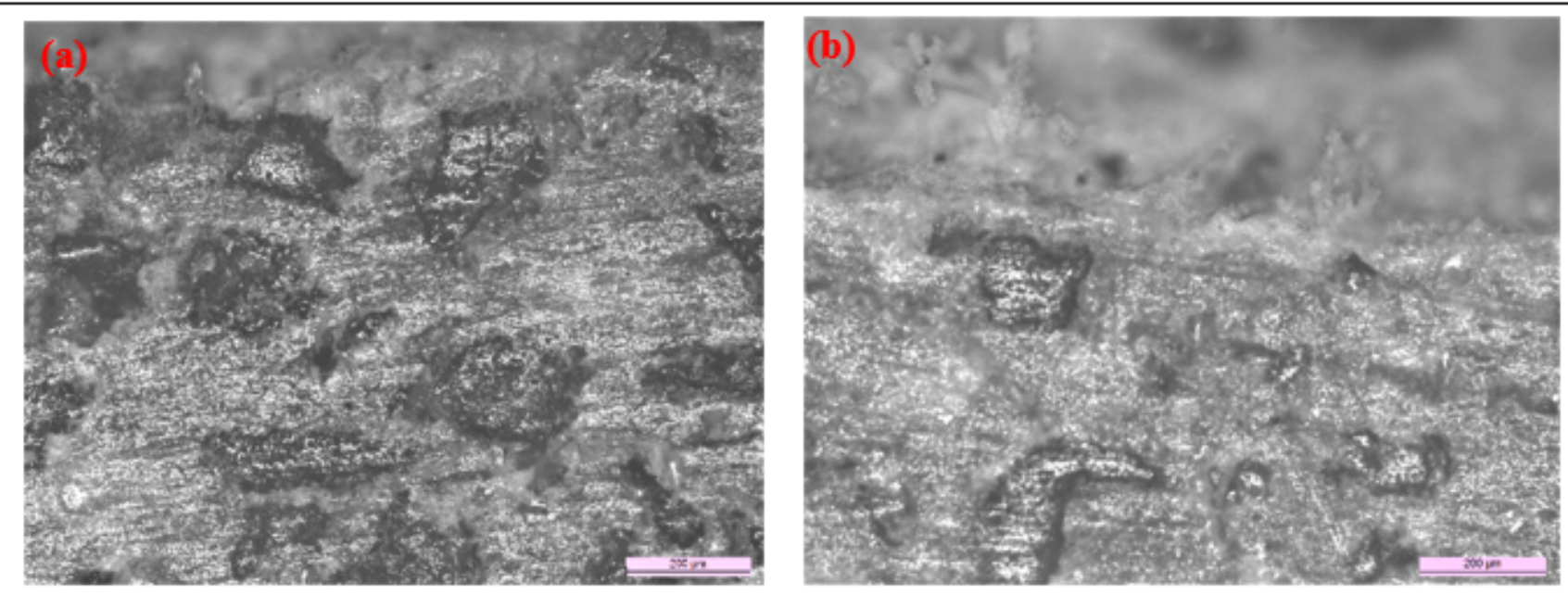

Figure 15 
Optical microscopic images of specimens at $34.335 \mathrm{~N}$ and $1.4369 \mathrm{~m} / \mathrm{s}$ (a) HDPE50 (b) HDPE60
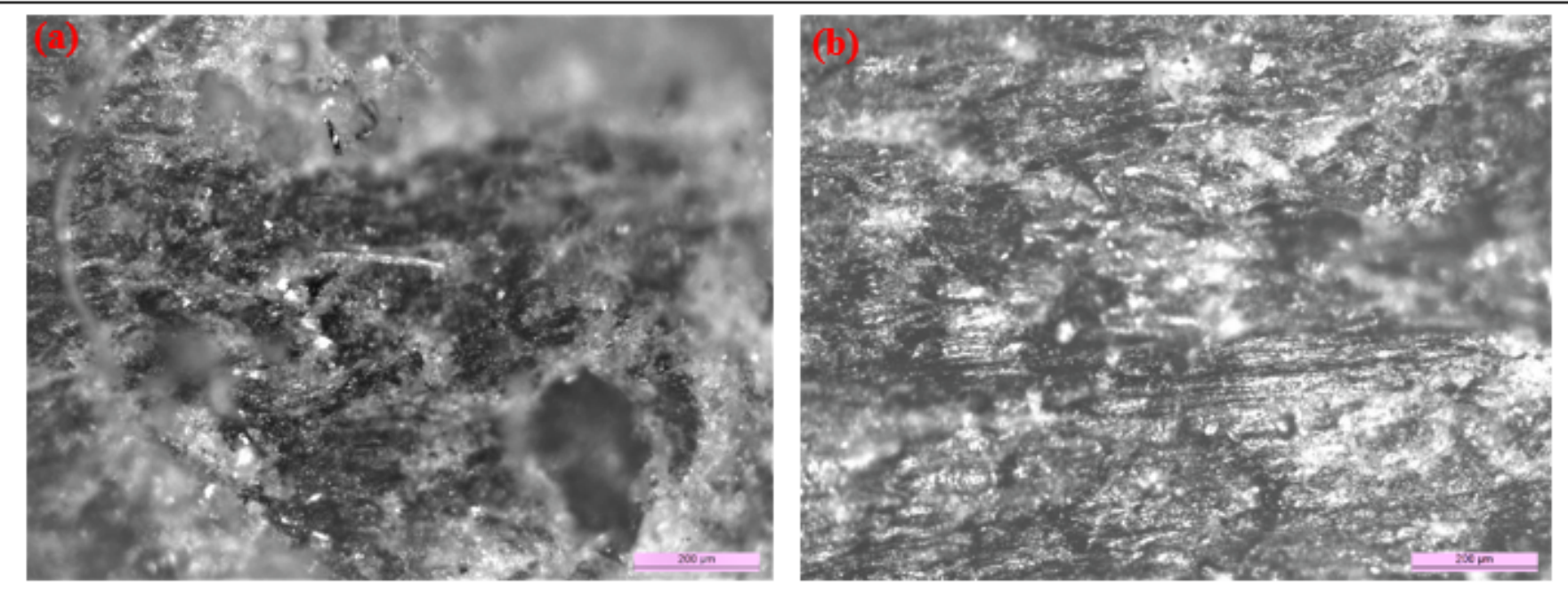

\section{Figure 16}

The worn surfaces of the LDPE specimen under (a) low load - $34.335 \mathrm{~N}$ and (b) high load - $90.742 \mathrm{~N}$
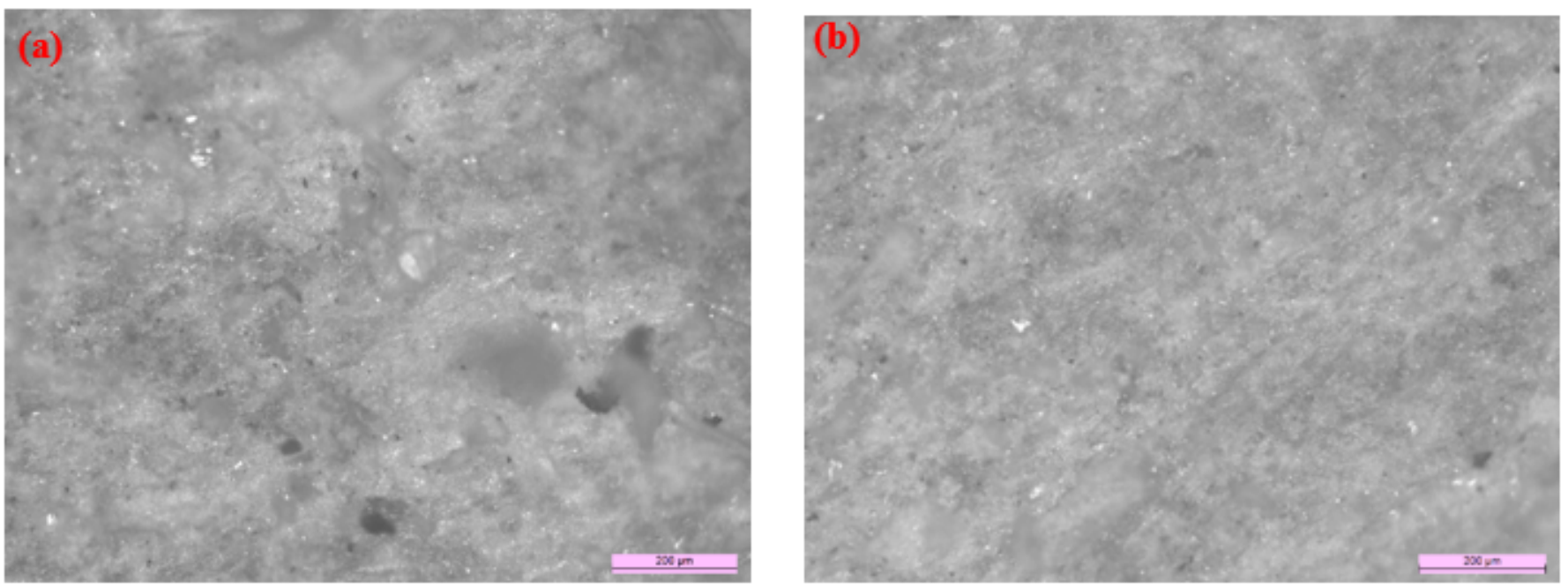

\section{Figure 17}

The worn surfaces of the HDPE specimen under (a) low load - 34.335 N and (b) high load - 90.742 N 


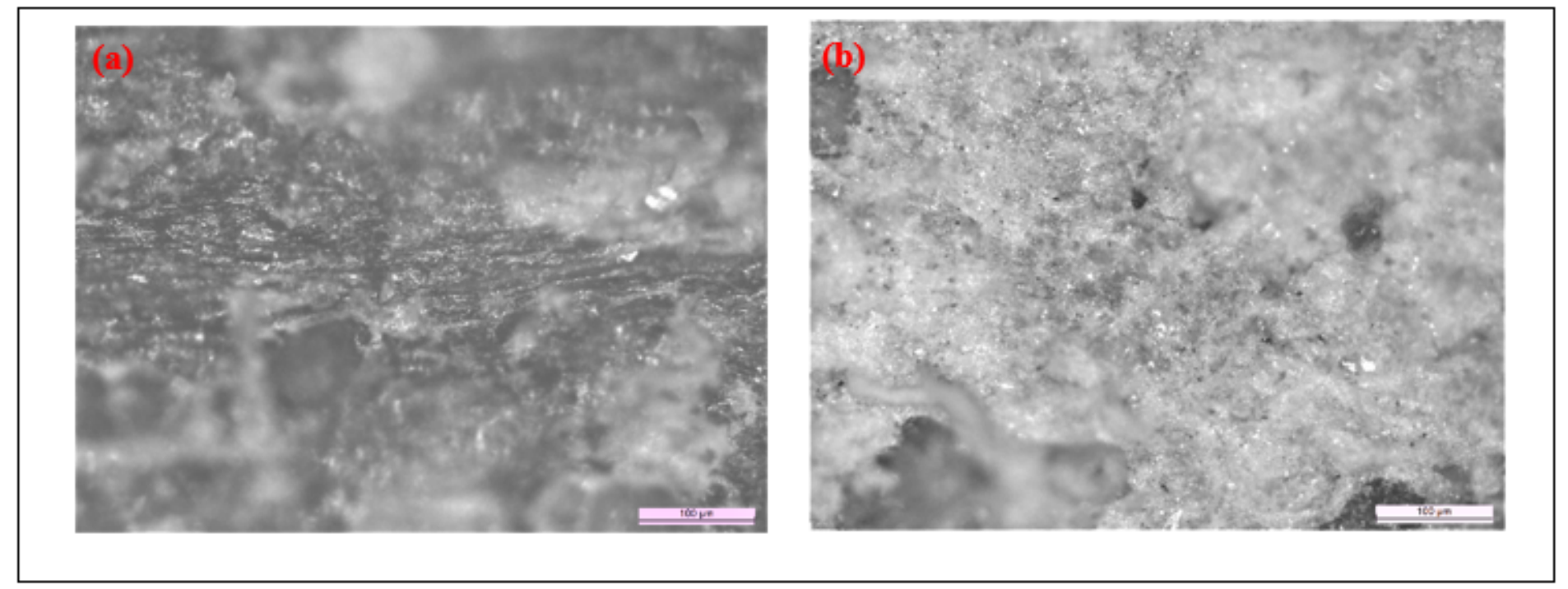

\section{Figure 18}

Images of the abraded surfaces at 56.898N (a) LDPE 70 (b) HDPE 70
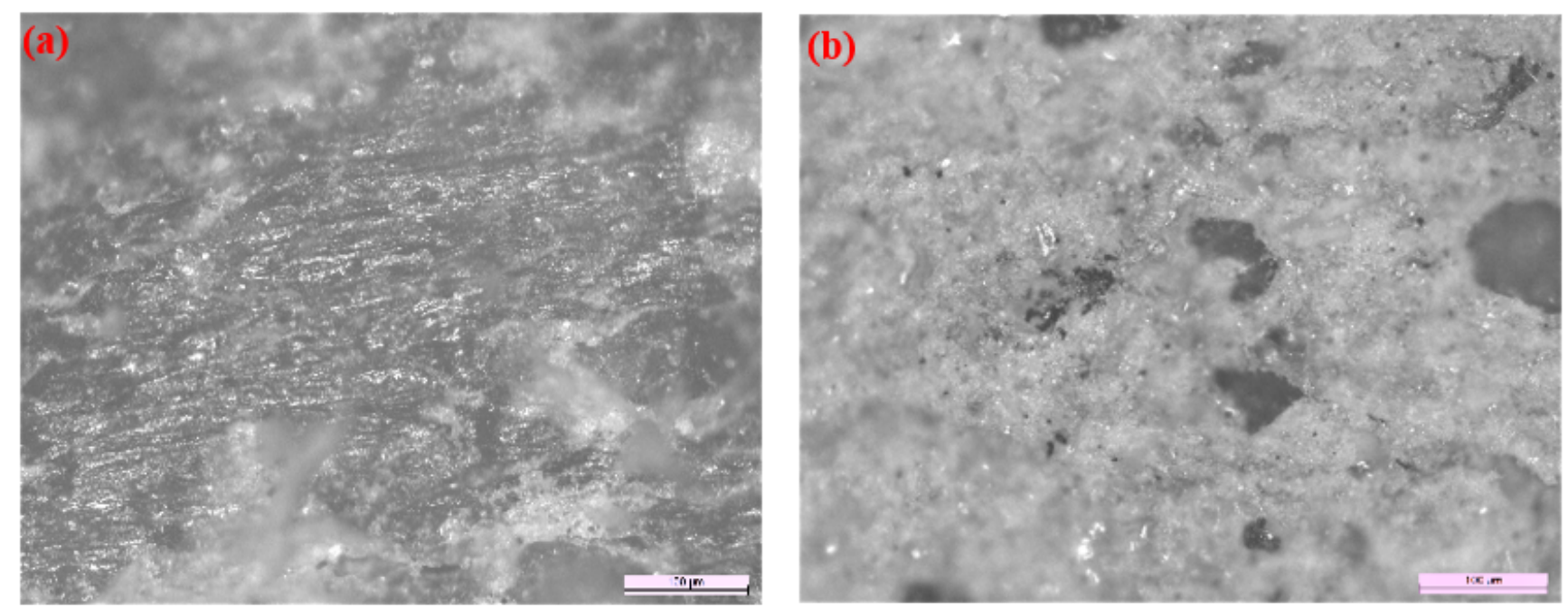

\section{Figure 19}

Images of the abraded surfaces at 68.179 N (a) LDPE 70 (b) HDPE 70 


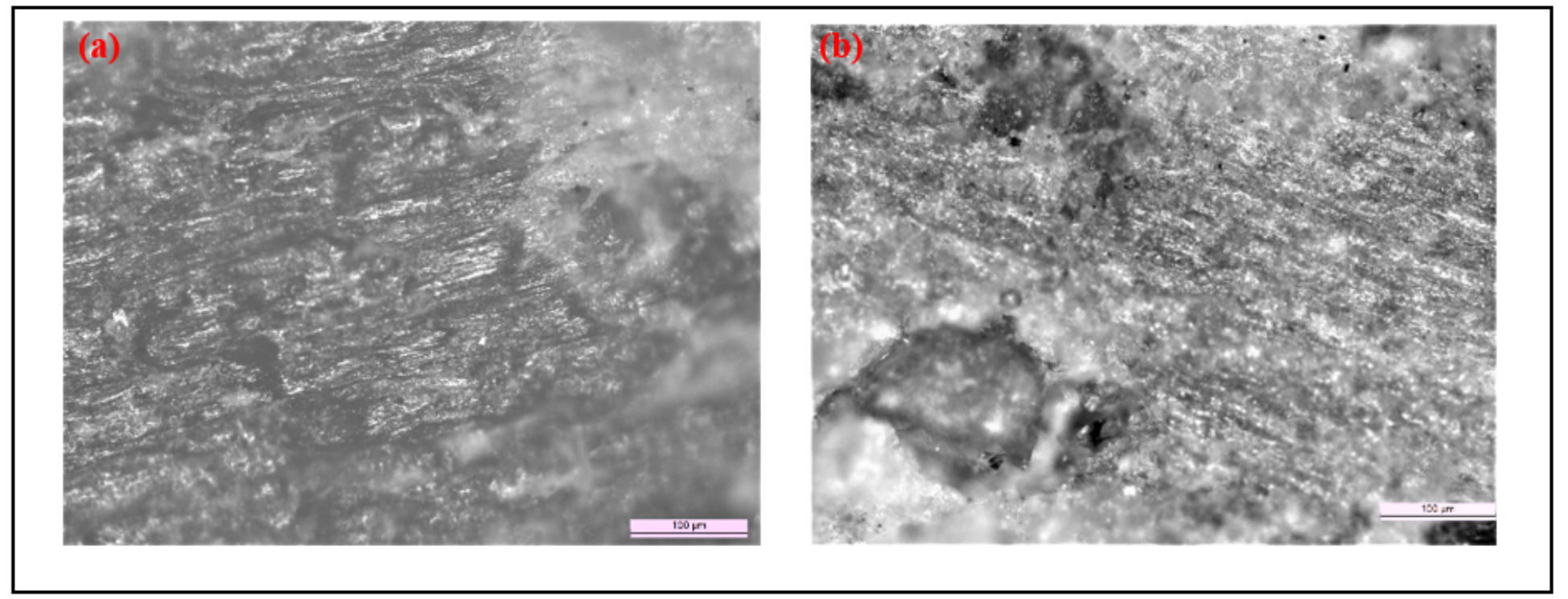

\section{Figure 20}

Images of the abraded surfaces at $79.461 \mathrm{~N}$ (a) LDPE 70 (b) HDPE 70 